\title{
Investigations on Microstructural Changes in Machining of Inconel 100 alloy using Face Turning Experiments and 3D Finite Element Simulations
}

\author{
Yiğit M. Arısoya, Changsheng Guo b, Bilgin Kaftanoğlu c, Tuğrul Özela,* \\ ${ }^{a}$ Rutgers, The State University of New Jersey, Department of Industrial \& Systems Engineering, New Jersey, USA \\ ${ }^{b}$ United Technologies Research Center, East Hartford, Connecticut, USA \\ ${ }^{c}$ ATILIM University, Department of Manufacturing Engineering, Ankara, Turkey
}

\begin{abstract}
Nickel-base IN100 alloy is a choice of material for components requiring high strength at elevated temperatures. Machining processes applied to these components affect the microstructure, grain size, and microhardness of the finished surface. This research investigates the effects of tool micro-geometry, coating, and cutting speed on the microstructural changes during machining. 3D customized finite element simulations have been performed to predict the average grain size by implementing modified temperature dependent flow softening based material and Johnson-Mehl-Avrami-Kolmogorov crystallization models. Simulation predictions on the average grain sizes, phase fractions, and resultant microhardness are compared against experimental measurements revealing good agreements.
\end{abstract}

Keywords: Cutting, Nickel alloy, Micro structure, Finite Element Method (FEM)

*Corresponding author, email: ozel@rutgers.edu, Phone +1 848-445-1099, Fax: +1 732-445-5467 


\section{Introduction}

Nickel-base alloys can maintain their strength at high temperatures and long exposures; therefore they are preferred for components in hot sections of the aircraft and gas turbine engines, nuclear reactors and rocket engines. They can be obtained through several different processing routes in the forms of wrought, forged, cast and in sintered i.e. powder metallurgy. Inconel 100 (IN100) is a Ni-Co-Cr based super alloy which is used in the cast or powder metallurgy (PM) forms and powder processing provides structural uniformity, high strength, and toughness suitable for engine components operating at intermediate temperature regimes such as disks, spacers, and seals where high strength at elevated temperatures and good corrosion resistance is maintained (Axinte et al. 2006).

Machining of nickel-base alloys is deemed to be extremely difficult due to their superior yield strength, rapid work hardening behavior, high rigidity, low thermal conductivity, chemical affinity to tool material, and microstructure related hard carbide particles (Ezugwu et al. 1999; Pawade et al. 2008). While excessive tool wear and part distortion issues remain to be solved, machining induced surface integrity is also a challenge to be addressed in nickel-base alloy part and component manufacturing. Machining processes can significantly affect finished part surface integrity which can be classified as surface topography related (textures, waviness and surface roughness), property related (residual stresses and microhardness), and metallurgical state (microstructure, phase transformation, grain size) characteristics. Extensive reviews of machining induced surface integrity have been provided in literature (Jawahir et al. 2011; Ulutan \& Özel 2011).

In addition, machining induced surface integrity and alterations to the subsurface microstructure so called "white layer" due to severe plastic deformation (SPD) and abusive thermal loading strongly affects the fatigue life of mission-critical components (M'Saoubi et al. 2014). Therefore, it is important to know the final state of the microstructure after the machining process and identify proper machining/tool parameters. This can be achieved through computational modeling and prediction. Finite Element (FE) based numerical simulations can be used to predict the grain size and microstructure and machining performance. Many different models exist for grain size prediction such as the Zener-Hollomon parameter based model (M'Saoubi et al. 2014) and the Johnson-MehlAvrami-Kolmogorov (JMAK) based recrystallization model (Shen et al. 1995; Shen 2005). The original JMAK model defines the crystallization kinetics in an isothermal process, and with certain modifications it can be utilized

to predict recrystallization during machining processes which are inherently anisothermal. Since dynamic recrystallization has been observed during machining of nickel-based alloys, the JMAK model together with 3D FE simulations will be utilized in this study.

\subsection{Microstructure of Inconel 100}

IN100 microstructure mainly consists of two phases; $\gamma$ and $\gamma^{\prime}$. An image of the IN100 microstructure obtained with Scanning Electron Microscopy (SEM) is given in Fig. 1. The $\gamma$ phase consists of large grains that form a matrix in the material whereas the strengthening $\gamma^{\prime}$ phases are formed as a result of various processes (Milligan et al. 2004; Wusatowska-Sarnek 2003a; 2003b; Kikuchi 1990). Three types of $\gamma^{\prime}$ have been observed: primary $\gamma^{\prime}$, secondary $\gamma^{\prime}$, 
and tertiary $\gamma^{\prime}$ (see Fig. 2). Sizes and distributions of these $\gamma^{\prime}$ precipitates are determined by process parameters, for instance, a very fine microstructure may be obtained by a subsolvus heat treatment. Milligan et al. (2004) states that by varying the cooling rate after the solutionizing step and the solution heat treatment temperature, it is possible to influence the $\gamma$ grain sizes as well as $\gamma^{\prime}$ grain sizes and distributions. It is stated by Wusatowska-Sarnek et al. (2003a) that primary $\gamma^{\prime}$ is affected by the solution treatment temperature, secondary $\gamma^{\prime}$ is affected by the stabilization temperature and forms during cooling from the solution temperature and tertiary $\gamma^{\prime}$ is controlled by aging. In addition, there are metal carbides in the microstructure (see Fig. 2). Carbides, in which carbon that is added in amounts of about 0.02 to $0.2 \mathrm{wt} \%$ combines with reactive elements, such as titanium, tantalum, hafnium, and niobium, to form metal carbides (MC). During heat treatment and service, these MC carbides tend to decompose and generate other carbides, such as $\mathrm{M}_{23} \mathrm{C}_{6}$, which tend to form at grain boundaries. Primary $\gamma^{\prime}$-grains are large enough to be compared with the $\gamma$-matrix grains, and can be included in the grain size measurement of the matrix.

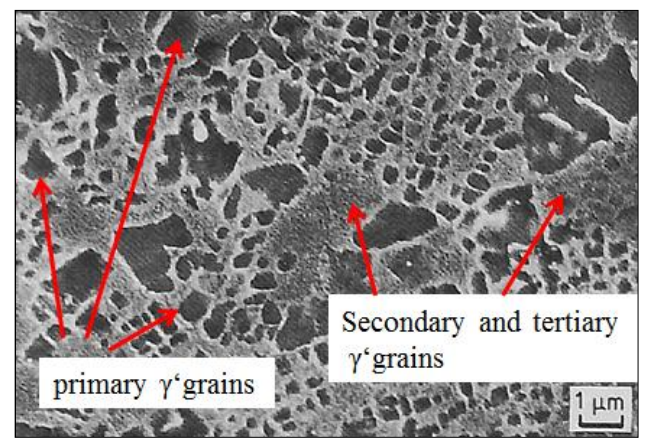

Fig. 1: Typical microstructure of IN100 alloy (Kikuchi 1990).

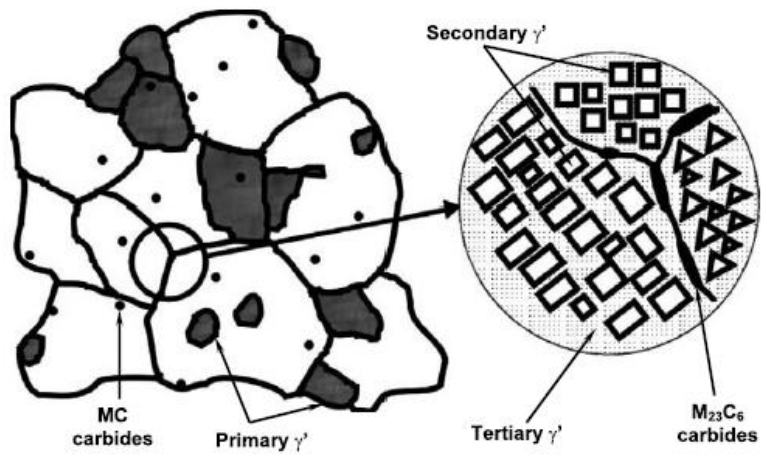

(a)

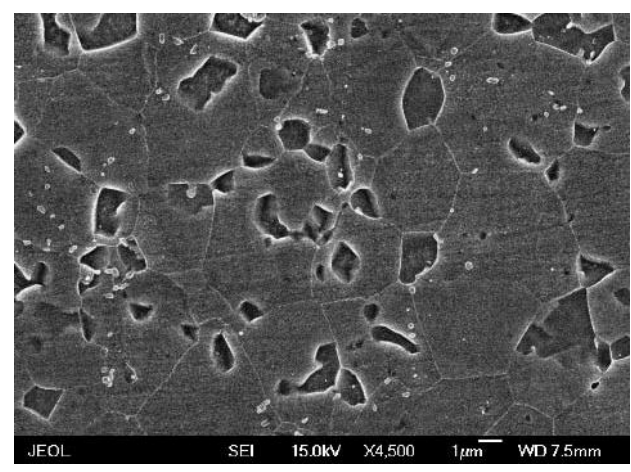

(b)

Fig. 2: Description of microstructural features in IN100 (a) (Wusatowska-Sarnek 2003a), SEM image of the microstructure of IN100 (b) (Wusatowska-Sarnek 2003b).

It was reported that the sizes and distributions of the $\gamma^{\prime}$ precipitates play an important role in mechanical properties of IN100. It is further stated by Wusatowska-Sarnek et al. (2003a) that a high strength material is obtained in the two phase field $\left(\gamma+\gamma^{\prime}\right)$ by maintaining the temperature below the $\gamma^{\prime}$ solvus, 1460K. A subsolvus solution treatment at $1416 \mathrm{~K}$ is followed by a two-step aging sequence at $1255 \mathrm{~K}$ and $1005 \mathrm{~K}$ to form the strengthening phases. Milligan 
et al. (2004) investigates the PM IN100 material with tensile tests at 260 and $650^{\circ} \mathrm{C}$ and states that secondary $\gamma^{\prime}$ size and volume fraction has a dominant effect on the strength of the material. It is further claimed that the presence of $\gamma^{\prime}$ is important, but its size is not. A decrease in strain hardening is observed with larger secondary $\gamma^{\prime}$ particles and with the presence of primary $\gamma^{\prime}$ particles.

Wusatowska-Sarnek et al. (2003b) reports the average IN100 $\gamma$-matrix grain size as $3.82 \mu \mathrm{m}$, Kikuchi et al. (1990) reports as $3.5 \mu \mathrm{m}$ and Milligan et al. (2004) reports as $4.2 \mu \mathrm{m}$ and primary $\gamma^{\prime}$-grains as $1.28 \mu \mathrm{m}$. Average secondary and tertiary $\gamma^{\prime}$-grains are nanocrystalline grains with average sizes of 100-120 nm and 8-20 nm respectively (see Table 1).

Figure 3 shows the microstructure of IN100 alloy produced via powder metallurgy and also $\gamma$ - and $\gamma^{\prime}$ - phases which is the focus of this paper. It is also widely reported that a different etching methods are required to reveal $\gamma$ - and $\gamma^{\prime}$ phases in the microstructure. The $\gamma^{\prime}$ - grains are large matrix grains and the boundaries are almost non-visible whereas primary and secondary $\gamma^{\prime}$-grains are visible when etched and their sizes and volume fractions are the most influential on hardness, strength and other mechanical properties of the material. Therefore, this study focuses on the microstructural changes that may occur due to thermal-mechanical processing of IN100 material with an emphasis on recrystallization of phases in $\gamma$ - and $\gamma^{\prime}$ - phases grains as measureable as possible.

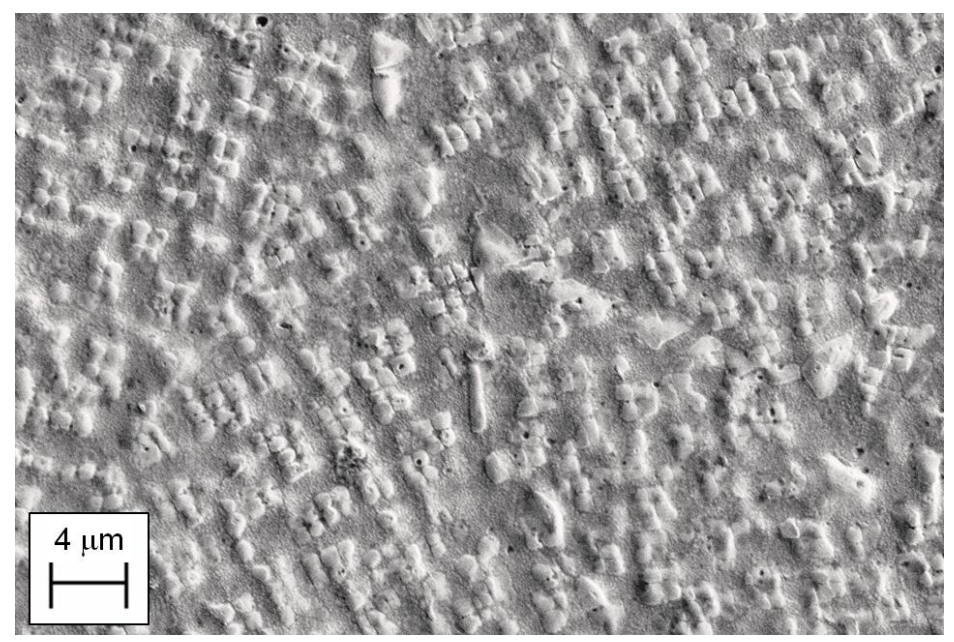

Fig. 3: Microstructure of IN100 alloy as reveled with electropolishing.

Table 1: Phases, typical grain sizes and volume fractions of IN100 nickel-base alloy (Milligan et al. 2004)

\begin{tabular}{|l|c|l|c|l|}
\hline Phase & Grain size & Value $[\boldsymbol{\mu m}]$ & Volume Fraction & Value \\
\hline $\boldsymbol{\gamma}$ grains & $\boldsymbol{d}_{\boldsymbol{a v g}}$ & $3.5-4.2$ & $\boldsymbol{f}_{\boldsymbol{0}}$ & balance \\
\hline Primary $\boldsymbol{\gamma}$ ' grains & $\boldsymbol{d}_{\boldsymbol{1}}$ & 1.28 & $\boldsymbol{f}_{\boldsymbol{I}}$ & 0.25 \\
\hline Secondary $\boldsymbol{\gamma}^{\prime}$ grains & $\boldsymbol{d}_{\boldsymbol{2}}$ & 0.109 & $\boldsymbol{f}_{\boldsymbol{2}}$ & 0.32 \\
\hline Tertiary $\boldsymbol{\gamma} \boldsymbol{\gamma}^{\prime}$ grains & $\boldsymbol{d}_{\boldsymbol{3}}$ & 0.021 & $\boldsymbol{f}_{\boldsymbol{3}}$ & 0.024 \\
\hline
\end{tabular}




\subsection{Microstructural changes in nickel-based alloys due to thermal-mechanical processing}

It is known that thermal-mechanical processing can cause several phenomenon-based changes in microstructure due to known effects of recrystallization, dislocation density, recovery and grain growth. Several researchers have investigated microstructural alterations in nickel-base super alloys under deformation. These investigations basically represent models involving characterization of dynamic structural changes (e.g. dynamic recrystallization (DRX)) and static structural changes (e.g. metadynamic recrystallization (MDRX), static recrystallization (SRX) and grain growth) (Shen et al. 1995). It should be noted that depending the level of deformation (strain and strain-rate) and temperature these structural changes are significantly affected. In hot-processing of nickel-based alloys including metal forming processes, static structural changes are typically caused by the time-temperature evolution and dynamic structural changes occur as a consequence of high plastic deformation level inducing flow softening and moderate to high temperatures (Zhang et al. 2004; Yuan and Liu 2005).

Shenoy et al. (2008) provided a detailed multiscale model and computational procedure to obtain a crystal plasticity model based on microstructure for the IN100 alloy using cyclic loading experiments at $650^{\circ} \mathrm{C}$. Shen et al. (1995) investigated Waspaloy undergoing thermomechanical processing and modelled dynamic recrystallization, metadynamic recrystallization and grain growth using Finite Element simulations. They found that the dynamic recrystallization kinetics is dependent on temperature, strain, strain rate and initial grain size. However, the dynamically recrystallized grain size did not depend on the initial grain size, and could be represented simply by using the Zener-Hollomon parameter, which is a function of strain rate, activation energy and temperature.

\subsection{Machining induced microstructural changes}

During machining of nickel-base super alloys, the microstructure is altered due to large plastic deformations and temperatures (Arunachalam et al. 2004; Aspinwall et al. 2007) which in turn affects the surface integrity of the end product. Work hardening is often observed during machining of IN100 which significantly increases the difficulty of machining this allow, and it is found to be linked to white layer formation. Ranganath et al. (2009) investigated the white layer formation in IN100 after machining using orthogonal cutting and Finite Element simulations. While the white layer formation was not detected due to relatively short cutting times, the effects of machining caused strain hardening was evident, with elongated grains near the machined surface. They also found out that low speed machining with large edge radius produced harder surfaces, with deformed layers being 2-3 times harder when compared to the bulk material.

Machining or chip formation process as a thermal-mechanical process with localized high temperature-gradients only present in the cutting zone and high plastic deformation levels that results in structural changes and recrystallization occurring dynamically significantly different that hot metal forming processes where predominantly static structural changes crystallization take place. At high plastic deformation levels, dynamic recrystallization happens instantaneously during high-temperature severe plastic deformations followed by meta-dynamic recrystallization immediately (Shen 2005). 
M'Saoubi et al. (2014) investigated the effect of abusive drilling on Nickel superalloys Alloy 718, Waspaloy, Alloy $720 \mathrm{Li}$ and RR1000 using material characterization analyses and nanoindentation testing. They observed nanometer sized grains in the severe plastic deformation (SPD) zone and plastic slip bands in subsurface layers. Nanoindentation results suggest a work hardening near the machining surface, and the Transmission Electron Microscopy (TEM) results showed an equiaxed ultra-fine grained microstructure that is attributed to recrystallization. They stated that RR1000 and Alloy 720Li exhibited a larger SPD zone and higher nanohardness compared to the other two allows. Additionally, the Zener-Hollomon parameter is used to estimate the grain size based on strain rate and temperature.

Özel \& Arisoy (2014), Arisoy \& Özel (2014) investigated the effects of machining process and cutting conditions on the hardness and microstructure of IN100 alloy. This study further investigates the microstructural changes in average sizes and volume fractions of $\gamma$ matrix grains as well as primary and secondary $\gamma^{\prime}$ grains with their calculated distributions, along with microhardness measurements at various depths below machined surfaces.

\section{Experimental Approach and Microstructure Investigations}

In order to investigate the effects of machining process on microstructural changes in Inconel IN100, Özel \& Arisoy (2014) has conducted a set of experiments by utilizing face turning of cylindrical disk specimens (see Fig. 4). IN100 alloy disks used in the original experiments are manufactured via powder metallurgy route with a chemical composition of $18.3 \% \mathrm{Co}, 12.4 \% \mathrm{Cr}, 3.2 \% \mathrm{Mo}, 4.9 \% \mathrm{Al}, 4.3 \% \mathrm{Ti}, 0.07 \% \mathrm{C}, 0.02 \% \mathrm{~B}, 0.027 \mathrm{Zr}$ and Ni balance. Machining experiments in face turning configuration were conducted to investigate the effects of machining/ tool parameters on the hardness and microstructure of IN100 alloy. A constant depth of cut ( $a_{p}=1 \mathrm{~mm}$ ), two cutting speed levels $\left(v_{c}=12\right.$ and $\left.24 \mathrm{~m} / \mathrm{min}\right)$ and a constant feed $(f=0.05 \mathrm{~mm} / \mathrm{rev})$ were used under dry (no-coolant) cutting conditions. Uncoated tungsten carbide in cobalt binder (WC/Co) cutting inserts with three different edge radii $\left(r_{\beta}\right)$ with $r_{\beta}=5 \pm 0.5 \mu \mathrm{m}$ (sharp edge), $r_{\beta}=10 \pm 0.7 \mu \mathrm{m}$ and $r_{\beta}=25 \pm 1.0 \mu \mathrm{m}$ were used. TiAlN coated inserts $\left(r_{\beta}=10 \pm 0.7 \mu \mathrm{m}\right)$ were also used. Cutting forces and residual stresses into the depth of the material under these experimental conditions were reported in earlier studies (Özel \& Ulutan 2012; Ulutan \& Özel 2013b; Arisoy \& Özel 2014; Ulutan et al. 2014). These authors have investigated the effects of cutting parameters on the resultant microstructure of IN100 where $a_{p}$ is the depth of cut, $F_{c}, F_{f}$, and $F_{p}$ are the cutting, feed, and thrust forces, and $r_{\beta}$ is the cutting edge radius of the tool. They have also reported that the measurement uncertainties for cutting, feed and thrust forces were between 5\%-10\%, 5\%-17\% and 9\%-39\%, respectively. 


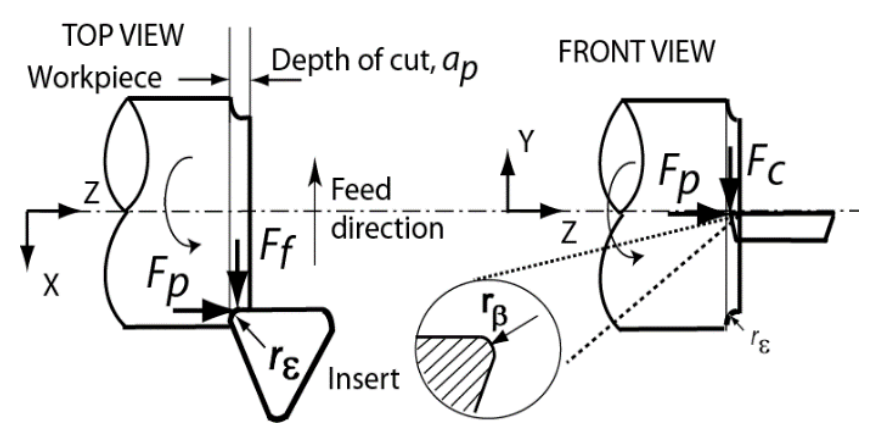

Fig. 4: Experimental configuration used in face turning (Özel \& Ulutan 2012).

For microhardness measurements and microstructural analysis, after face turning, approximately 3-4 mm thick disks from the machined section were obtained by cutting-off about $5 \mathrm{~mm}$ away from the surface of the disk and cleaning the new surface with very gentle machining. During the tests, a constant depth of cut ( $a_{p}=1 \mathrm{~mm}$ ), two cutting speed levels $\left(v_{c}=12\right.$ and $\left.24 \mathrm{~m} / \mathrm{min}\right)$ and a constant feed $(f=0.05 \mathrm{~mm})$ were used under dry cutting conditions. In these experiments, uncoated cutting inserts made of tungsten carbide in cobalt binder (WC/Co) with up-sharp (edge radius of $r_{\beta}=5 \pm 0.5 \mu \mathrm{m}$ as measured) and edge prepared with abrasive brushing for $r_{\beta}=25 \pm 1.0 \mu \mathrm{m} \mu \mathrm{m}$ (WC25) and $r_{\beta}=10 \pm 0.7 \mu \mathrm{m}$ (WC10), and TiAlN coated inserts $\left(r_{\beta}=10 \pm 0.7 \mu \mathrm{m}\right.$ as measured) have been used. Each cutting edge was only used once to minimize the effect of tool wear.

\subsection{Microhardness measurements}

In order to better understand the effects of machining on the surface integrity of IN100 parts, a series of experiments have been conducted that investigate the microhardness and microstructure of the surfaces processed with cutting conditions explained in the previous section. Microhardness measurements from the machined disk specimens were conducted at Metal Forming Forming Center of Excellence at Atilim University. The experimental procedure followed includes removing the surface layers to reach the depths of $0.010,0.025,0.050,0.080,0.120 \mathrm{~mm}$ by using Struers LectroPol-5 electro-polishing machine. For removing the surface layers Struers A2 electrolyte at voltage of $20 \mathrm{~V}$ was used. The duration of electro-polishing was varied between 20 and 330 seconds to reach the desired depth. The depth of the removed layer was ensured by dial gauge readings. After the removal of the prescribed layer, Vickers microhardness measurements from exposed surfaces with Zwick/ Roell ZHV 10 microhardness tester using a load of $19.61 \mathrm{~N}$ at a test speed of $25 \mathrm{~mm} / \mathrm{min}$ have been taken. At each depth level, 5 hardness readings were taken from the surface for replication.

Effects of the cutting conditions and tool coatings on microhardness are observed by using the microhardness measurements on the machined surfaces as Vickers Hardness (HV) into the depth as summarized in Fig. 5. The error bars represent the standard deviations of the measurements at each depth. In addition, the percentage change of the hardness difference between surface and bulk hardness in Vickers hardness is given in Table 2.

Overall, a depth of severe plastic deformation (SPD) about $25 \mu \mathrm{m}$ has been observed from microhardness profiles. Increasing tool edge radius caused a higher hardness profile into the depth at both cutting speeds. In general, the 
TiAlN coated $r_{\beta}=10 \pm 0.7 \mu \mathrm{m}$ tool provided lowest hardness profile into the depth of the alloy material, along with the uncoated sharp WC/Co $r_{\beta}=5 \pm 0.5 \mu \mathrm{m}$ tool. Increasing cutting speed decreased the hardness but increased hardness variations indicating possible microstructural changes due to dynamic recrystallization. Among the cutting conditions used for IN100 alloy, it is observed that uncoated WC/Co tool with $r_{\beta}=25 \mu \mathrm{m}$ produced abusively severe deformation field and hardest subsurface which should be avoided in industrial applications where machinability is important.

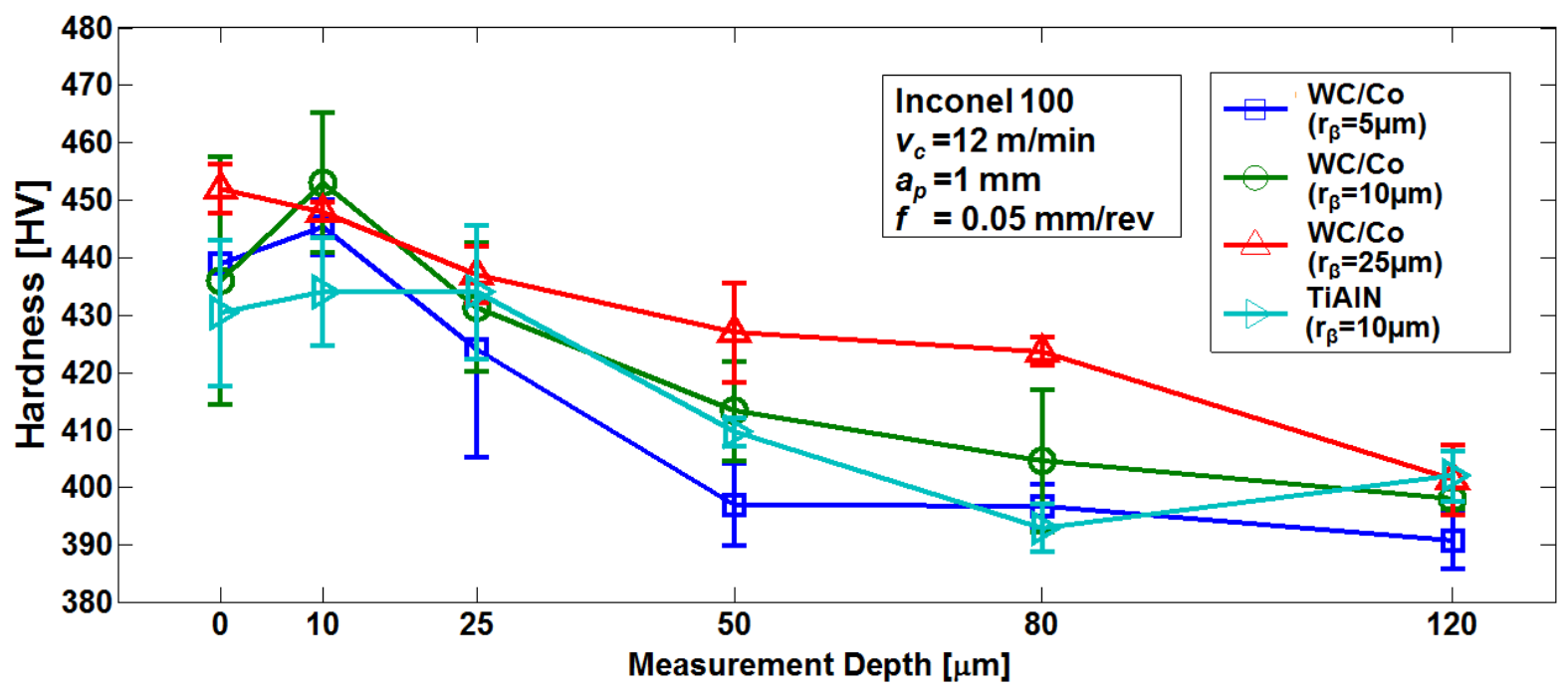

(a)

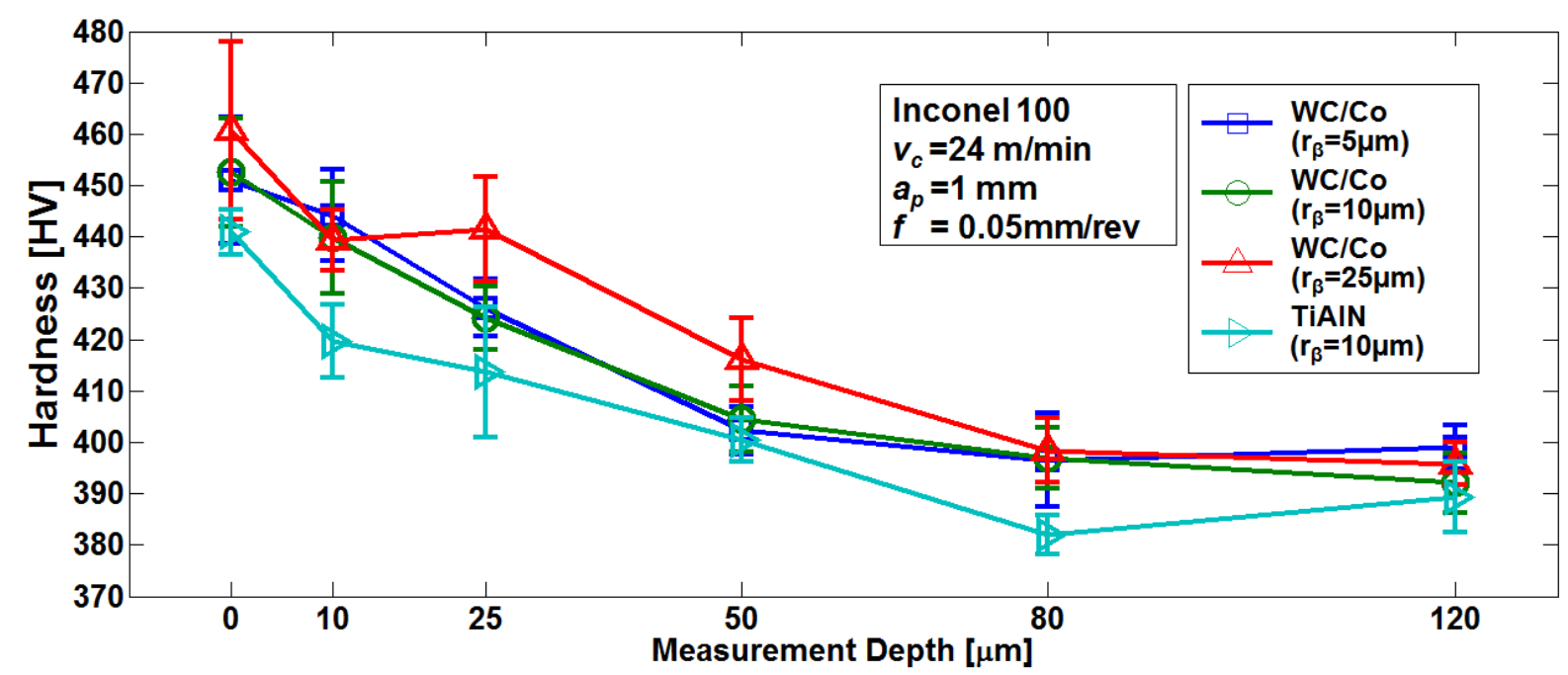

(b)

Fig. 5: Measured microhardness profiles of machined IN100 subsurface into depth: (a) cutting speed $v_{c}=12$ $\mathrm{m} / \mathrm{min}$, and (b) $v_{c}=24 \mathrm{~m} / \mathrm{min}$ (depth of cut $a_{p}=1 \mathrm{~mm}$, feed $f=0.05 \mathrm{~mm} / \mathrm{rev}$ under dry cutting conditions). 
Table 2: Percentage differences in measured surface and bulk (388 HV) Vickers hardness

\begin{tabular}{|c|c|c|c|c|}
\hline \multirow{2}{*}{ Tool } & $\begin{array}{c}\boldsymbol{v}_{\boldsymbol{c}} \\
{[\mathrm{m} / \mathbf{m i n}]}\end{array}$ & $\begin{array}{c}\boldsymbol{f} \\
{[\mathrm{mm} / \mathbf{r e v}]}\end{array}$ & $\begin{array}{c}\text { Surface hardnessDifference } \\
{[\mathbf{H V}]}\end{array}$ & {$[\%]$} \\
\hline \multirow{2}{*}{ WC/Co, $r_{\beta}=5 \mu \mathrm{m}$} & 12 & 0.05 & 439 & 13.1 \\
\cline { 2 - 5 } & 24 & 0.05 & 452 & 16.5 \\
\hline \multirow{2}{*}{ TiAlN, $r_{\beta}=10 \mu \mathrm{m}$} & 12 & 0.05 & 430 & 10.8 \\
\cline { 2 - 5 } & 24 & 0.05 & 440 & 13.4 \\
\hline \multirow{2}{*}{$\mathrm{WC} / \mathrm{Co}, r_{\beta}=10 \mu \mathrm{m}$} & 12 & 0.05 & 435 & 12.1 \\
\hline \multirow{2}{*}{ WC/Co, $r_{\beta}=25 \mu \mathrm{m}$} & 12 & 0.05 & 452 & 16.5 \\
\cline { 2 - 5 } & 24 & 0.05 & 460 & 18.6 \\
\hline
\end{tabular}

\subsection{Predictive models for machining induced hardness}

A practical aspect of understanding machining induced hardness alterations is to utilize some mathematical expressions to represent the relationship between cutting conditions and resultant hardness at the machined surfaces and into the depth of the material. By utilizing the experimental data, it is possible to create models that relate the cutting conditions such as cutting speed and tool edge radius to microhardness at different depths from the surface.

Two separate models have been created to relate the cutting conditions to hardness, via regression. The first model predicts the hardness with respect to depth and cutting speed $v_{c}$ for the TiAlN coated tool, using an exponentially decaying function to represent the depth, and is given by:

$$
H V=396.05+51.09 v_{c}^{-0.002} e^{-0.02 h}-0.14 v_{c}^{1.46}
$$

where $h$ is the positive depth below surface. For the uncoated tools with edge radii $r_{\beta}=5 \mu \mathrm{m}, 10 \mu \mathrm{m}$ and $25 \mu \mathrm{m}$, the tool edge radius has been included in the model, resulting in Eq. (2).

$$
H V=389.51+54.61 v_{c}^{0.09} r_{\beta}{ }^{-0.05} e^{-0.02 h}-1.17 v_{c}^{0.72}+0.86 r_{\beta}{ }^{0.93}
$$

The $\mathrm{R}^{2}$ values for Eqs. (1) and (2) are found as 0.87 and 0.91, respectively. Note that more complicated models with additional terms can be constructed at the expense of generalization power. 
Fig. 6 shows the surface that is obtained from Eq. (1) for TiAlN coated WC/Co cutting tool while Figs. 7 through 9 show the surfaces obtained from Eq. (2) for uncoated WC/Co tools at different tool edge radii. Three different surfaces are shown in Figs. 7-9 by keeping the tool edge radius constant.

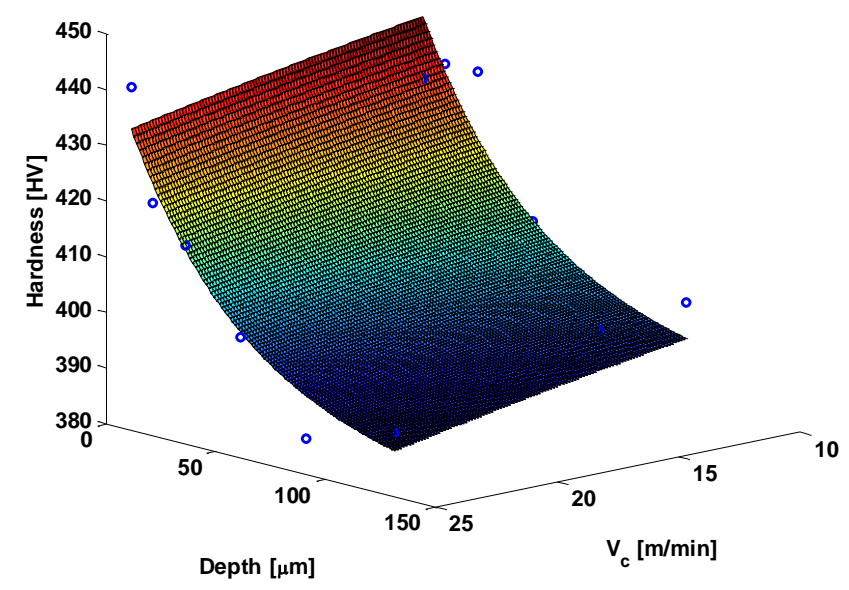

Fig. 6: Surface fit of the microhardness with respect to depth and cutting speed for the TiAlN coated tool. Experimental data points are shown as circles.

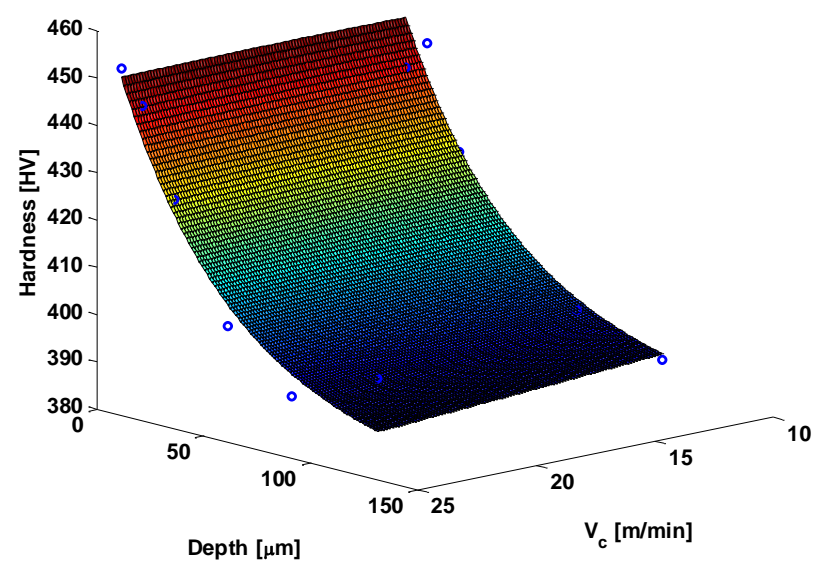

Fig. 7: Surface fit of the microhardness with respect to depth and cutting speed for the uncoated tools with $r_{\beta}=5 \mu \mathrm{m}$. Experimental data points are shown as circles. 


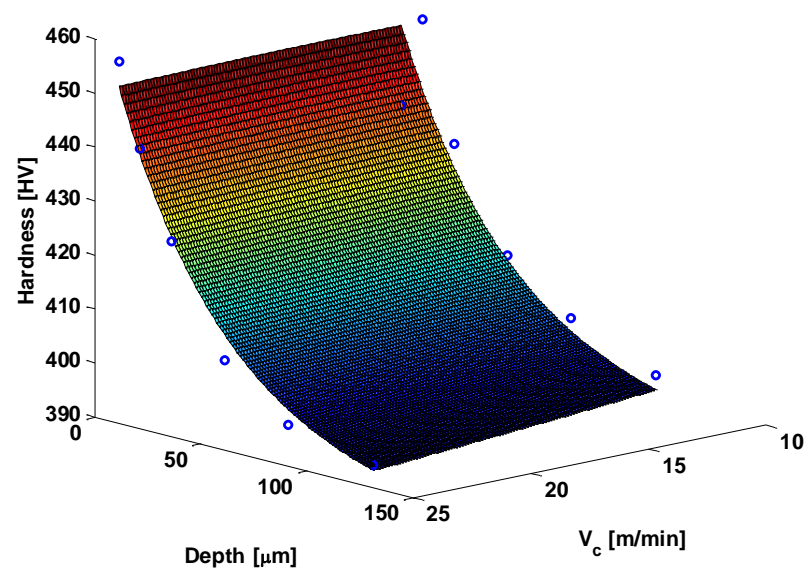

Fig. 8: Surface fit of the microhardness with respect to depth and cutting speed for the uncoated tools with $r_{\beta}=10 \mu \mathrm{m}$. Experimental data points are shown as circles.

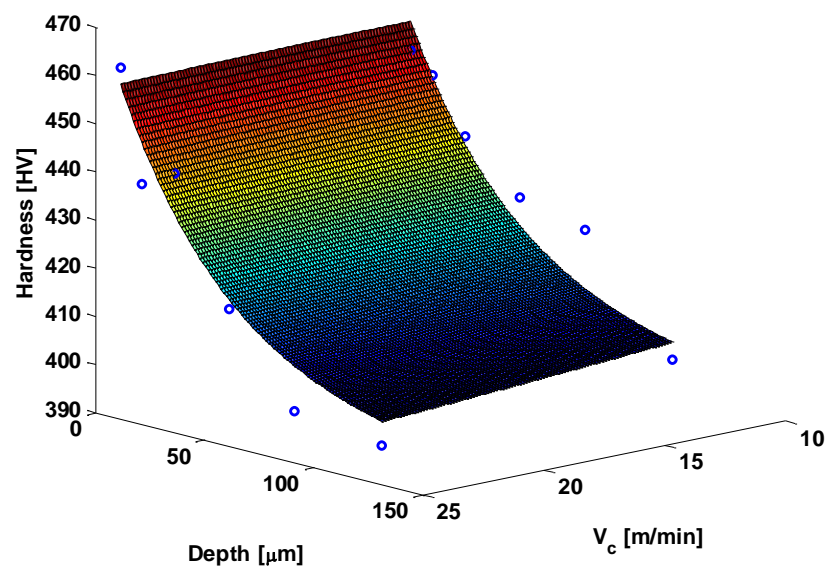

Fig. 9: Surface fit of the microhardness with respect to depth and cutting speed for the uncoated tools with $r_{\beta}=25 \mu \mathrm{m}$ edge radii. Experimental data points are shown as circles.

\subsection{Microstructural measurements}

Microstructure of the machined surfaces has also been investigated to obtain a better understanding of the underlying causes of the microhardness alterations discussed in the previous section. The microstructure of IN100 alloy consists of two phases i.e. $\gamma$ and $\gamma^{\prime}$. The face-centered-cubic austenitic $\gamma$ phase consists of large grains (3-4 $\left.\mu \mathrm{m}\right)$ that form the matrix in the material whereas precipitating $\gamma^{\prime}$ phase grains $(<1.5 \mu \mathrm{m})$ are formed as a result of various processes (Kikuchi et al. 1990). Three sizes of $\gamma^{\prime}$ grains have been observed: primary $\gamma^{\prime}(1.25-1.3 \mu \mathrm{m}$ with $25 \%$ volume fraction), secondary $\gamma^{\prime}\left(\sim 0.1 \mu \mathrm{m}\right.$ with $32 \%$ volume fraction) and tertiary $\gamma^{\prime}(\sim 20 \mathrm{~nm}$ with $0.24 \%$ volume fraction) (Wusatowska-Sarnek et al. 2003; Milligan et al. 2004). It is widely reported that the machining process, in which high temperatures combined with high strain-rate large plastic deformations are generated, affects microstructure and grain size (Arrazola et al. 2013; M'Saoubi et al. 2014). Therefore dynamic recrystallization is 
expected to occur in the regions of sufficient exposure to those processing conditions at about $0.2-0.5 \times T_{m}\left(T_{m}\right.$ $=1320^{\circ} \mathrm{C}$ for IN100).

It is reported that different etching methods should be applied to reveal the structural features and for identification each phase in IN100 due to the microstructural complexity of the alloy (Wusatowska-Sarnek et al. 2003a). In this study, microstructural analysis was performed beginning with preparing the IN100 disk specimens by electropolishing the machined surfaces in order to reveal the underlying microstructure primarily $\gamma^{\prime}$ grains and fractions. Since the boundaries of the $\gamma$-matrix grains were not clearly revealed, there were no measurements taken on machining affected $\gamma$-matrix grain sizes. Similarly, tertiary $\gamma^{\prime}$ grains could not be measured since they are extremely small in the order of nanometers as reported by Milligan et al. 2014. Scanning electron microscopy (SEM) was used to obtain images of the prepared surfaces. Grain diameters and area fractions were determined from the SEM images via an in-house developed image processing code written in MATLAB. Grains were first marked and their areas were calculated so that a histogram for their sizes and frequency of occurrence was obtained.

Figures 10-17 show the processed SEM images together with identified zones of primary and secondary $\gamma^{\prime}$ grains. In addition, the distribution of primary and secondary $\gamma^{\prime}$ grain sizes are given with histograms in each figure. Furthermore, measured grain sizes $\left(d_{1}\right.$ primary $\gamma^{\prime}, d_{2}$ secondary $\left.\gamma^{\prime}\right)$ with their means and standard deviations (SD) and volume fractions ( $f_{1}$ primary $\gamma^{\prime}, f_{2}$ secondary $\left.\gamma^{\prime}\right)$ are given as a summary in Table 3. It should be noted that there is no measurement reported on $\gamma$-matrix grains and tertiary $\gamma^{\prime}$ grains due to the explained difficulties.

Tertiary $\gamma^{\prime}$ precipitates are too small to be measured with the current methodology, therefore tertiary $\gamma^{\prime}$ sizes $\left(d_{3}\right)$ and volume fractions $\left(f_{3}\right)$ are assumed to remain unaffected by different machining operations for modeling purposes and are taken as $d_{3}=10 \mathrm{~nm}$ and $f_{3}=0.042$ (Milligan et al. 2004) in the predictive modeling studies that are discussed later.

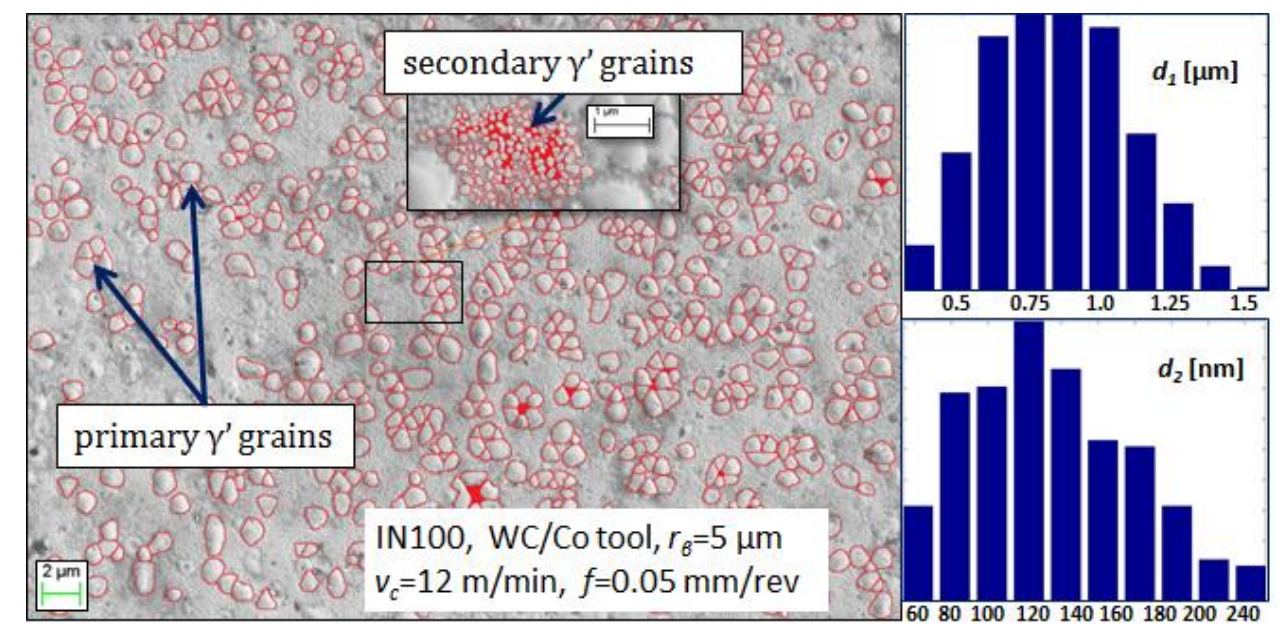

Fig. 10: Microstructure of machined IN100 subsurface (Sharp WC/Co tool, $v_{c}=12 \mathrm{~m} / \mathrm{min}, f=0.05 \mathrm{~mm} / \mathrm{rev}$ ), histograms of primary $\gamma^{\prime}\left(d_{1}\right)$ and secondary $\gamma^{\prime}\left(d_{2}\right)$ grains. Grains are marked red. 


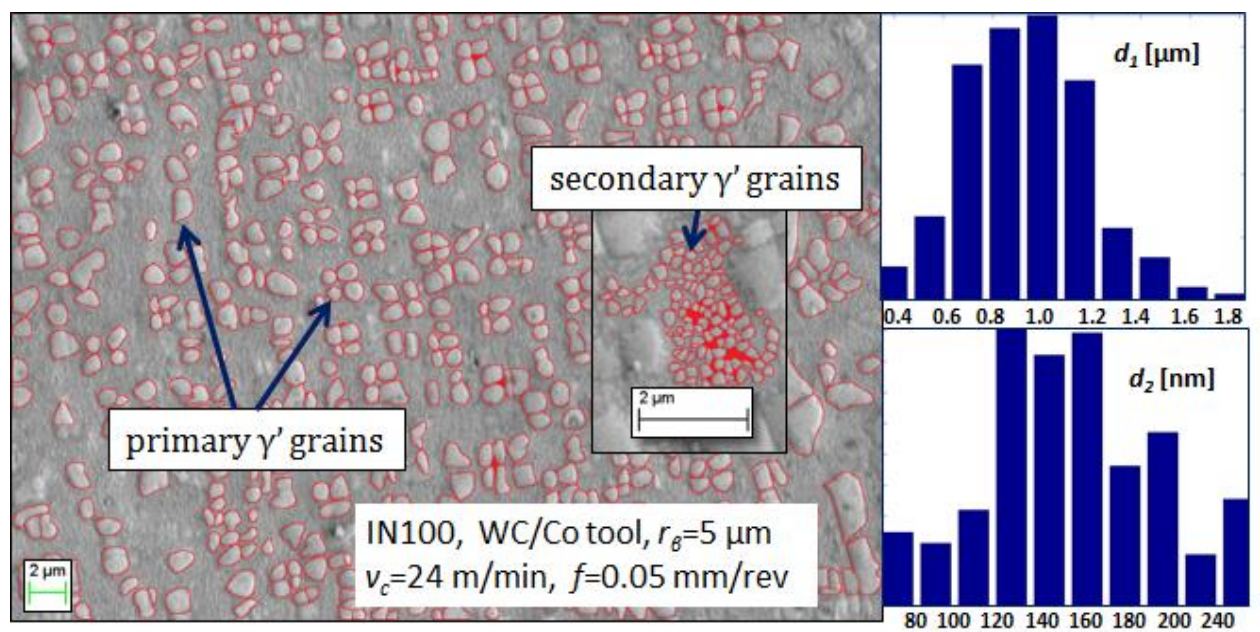

Fig. 11: Microstructure of machined IN100 subsurface (Sharp WC/Co tool, $v_{c}=24 \mathrm{~m} / \mathrm{min}, f=0.05 \mathrm{~mm} / \mathrm{rev}$ ), histograms of primary $\gamma^{\prime}\left(d_{1}\right)$ and secondary $\gamma^{\prime}\left(d_{2}\right)$ grains. Grains are marked red.

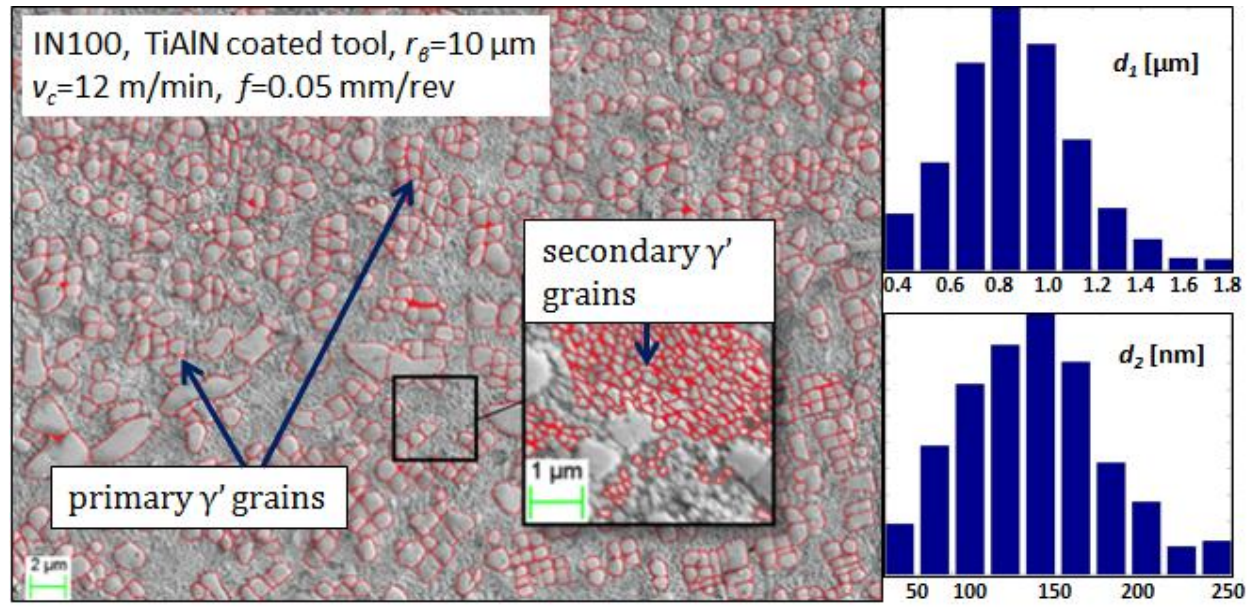

Fig. 12: Microstructure of machined IN100 subsurface (TiAlN coated WC/Co tool, $v_{c}=12 \mathrm{~m} / \mathrm{min}, f=0.05$ $\mathrm{mm} / \mathrm{rev})$, histograms of primary $\gamma^{\prime}\left(d_{1}\right)$ and secondary $\gamma^{\prime}\left(d_{2}\right)$ grains. Grains are marked red. 


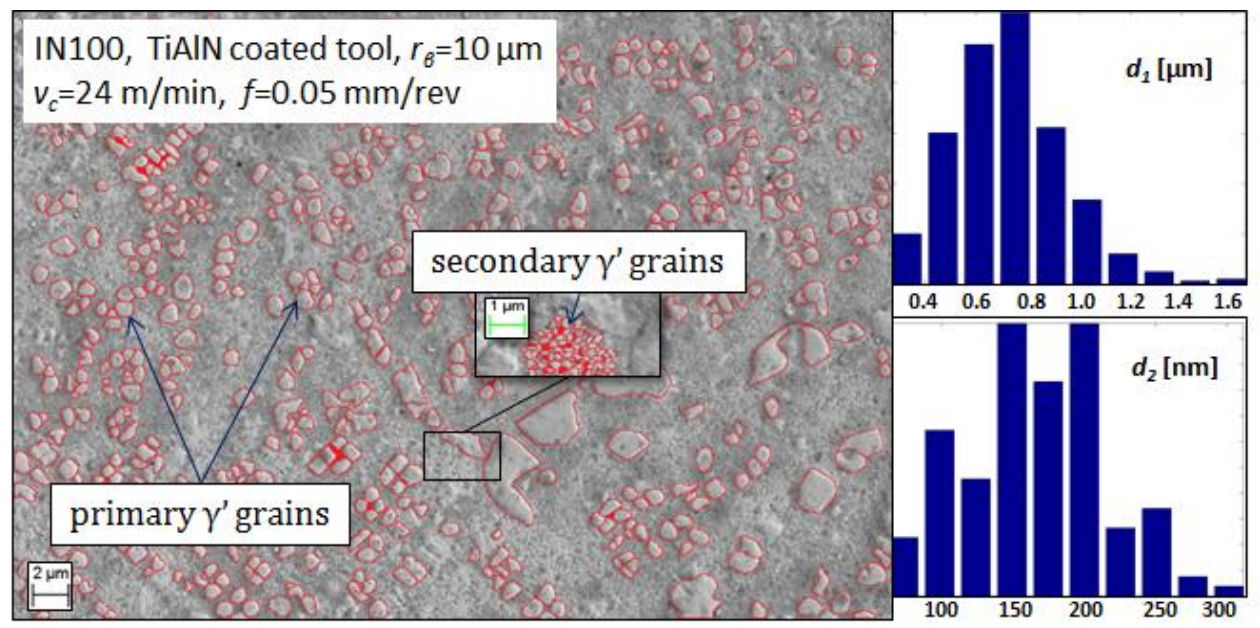

Fig. 13: Microstructure of machined IN100 subsurface (TiAlN coated WC/Co tool, $v_{c}=24 \mathrm{~m} / \mathrm{min}, f=0.05$ $\mathrm{mm} / \mathrm{rev})$, histograms of primary $\gamma^{\prime}\left(d_{1}\right)$ and secondary $\gamma^{\prime}\left(d_{2}\right)$ grains. Grains are marked red.

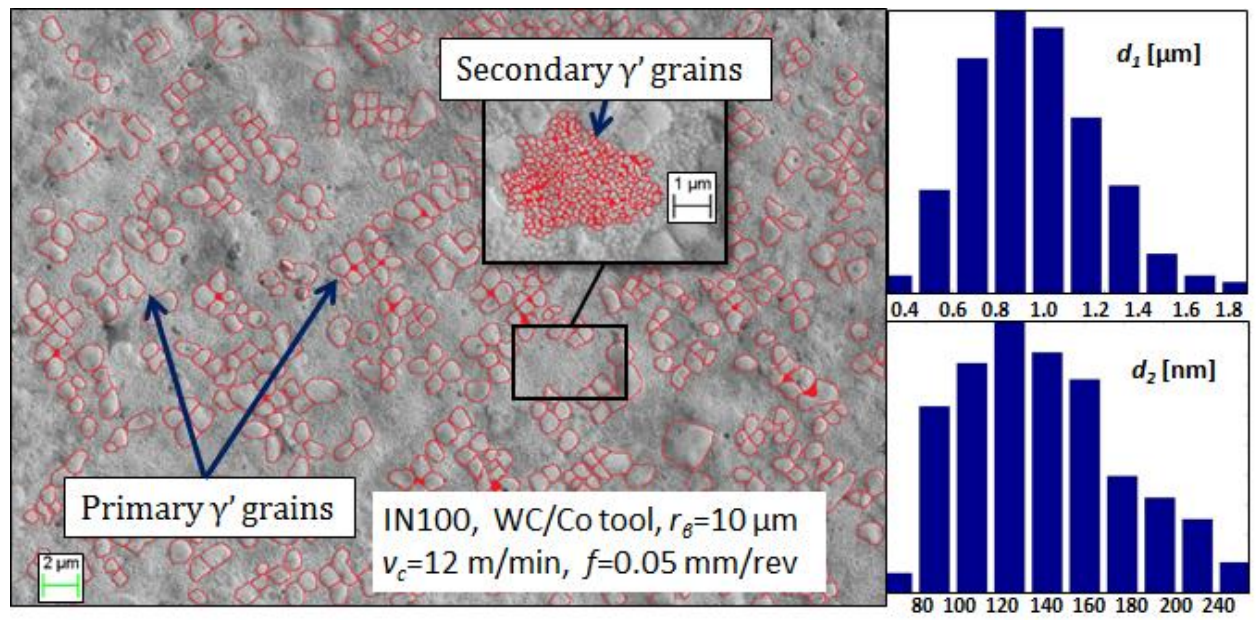

Fig. 14: Microstructure of machined IN100 subsurface (WC/Co $r_{\beta}=10 \mu \mathrm{m}$ tool, $v_{c}=12 \mathrm{~m} / \mathrm{min}, f=0.05 \mathrm{~mm} / \mathrm{rev}$ ), histograms of primary $\gamma^{\prime}\left(d_{1}\right)$ and secondary $\gamma^{\prime}\left(d_{2}\right)$ grains. Grains are marked red. 


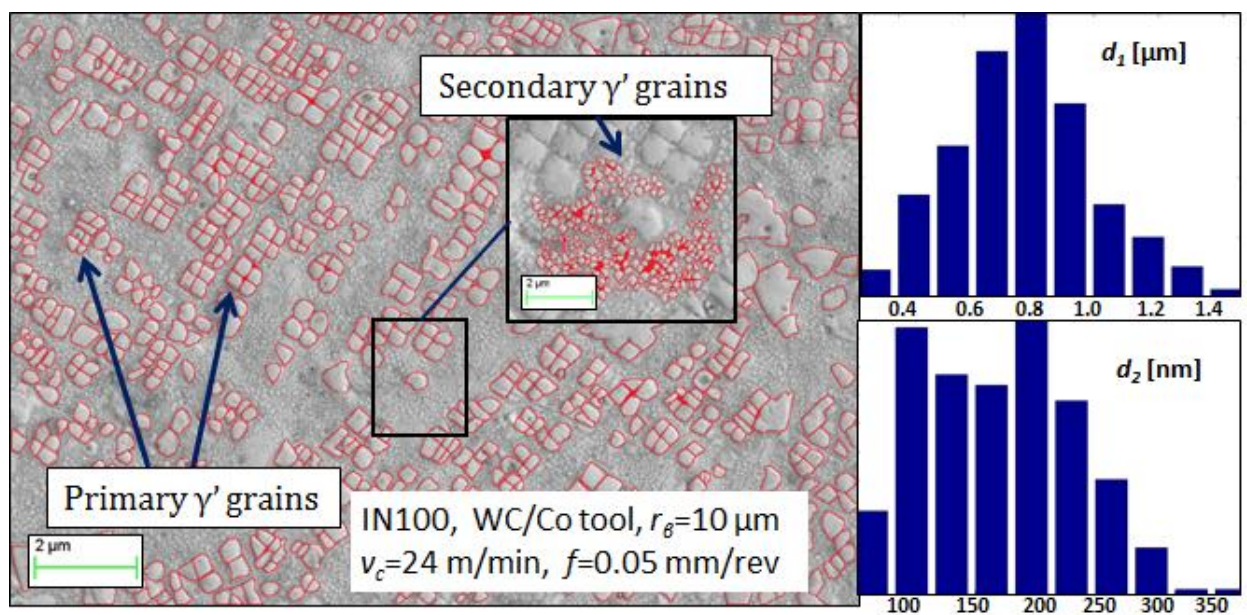

Fig. 15: Microstructure of machined IN100 subsurface (WC/Co $r_{\beta}=10 \mu \mathrm{m}$ tool, $v_{c}=24 \mathrm{~m} / \mathrm{min}, f=0.05 \mathrm{~mm} / \mathrm{rev}$ ), histograms of primary $\gamma^{\prime}\left(d_{1}\right)$ and secondary $\gamma^{\prime}\left(d_{2}\right)$ grains. Grains are marked red.

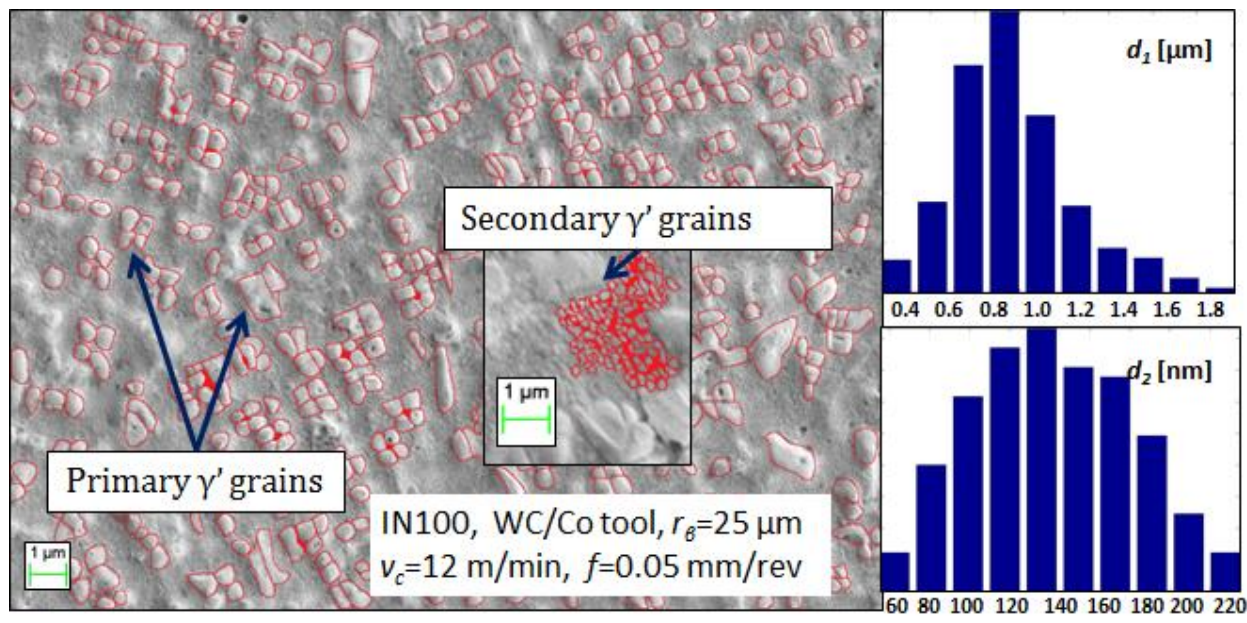

Fig. 16: Microstructure of machined IN100 subsurface (WC/Co $r_{\beta}=25 \mu \mathrm{m}$ tool, $v_{c}=12 \mathrm{~m} / \mathrm{min}, f=0.05 \mathrm{~mm} / \mathrm{rev}$ ), histograms of primary $\gamma^{\prime}\left(d_{1}\right)$ and secondary $\gamma^{\prime}\left(d_{2}\right)$ grains. Grains are marked red. 


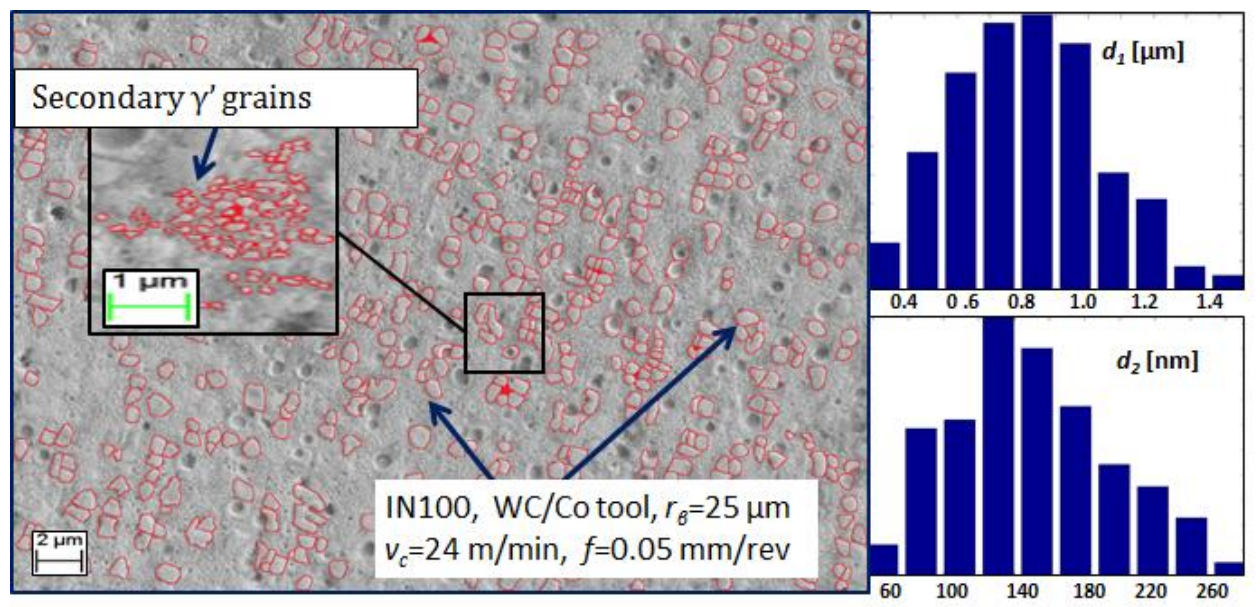

Fig. 17: Microstructure of machined IN100 subsurface (WC/Co $r_{\beta}=25 \mu \mathrm{m}$ tool, $v_{c}=24 \mathrm{~m} / \mathrm{min}, f=0.05 \mathrm{~mm} / \mathrm{rev}$ ), histograms of primary $\gamma^{\prime}\left(d_{1}\right)$ and secondary $\gamma^{\prime}\left(d_{2}\right)$ grains. Grains are marked red. 
Table 3: Measured average grain sizes and volume fractions after material machining.

\begin{tabular}{|c|c|c|c|c|c|c|c|c|}
\hline \multirow[b]{2}{*}{ Tool } & \multirow{2}{*}{$\begin{array}{c}v_{c} \\
{[\mathrm{~m} / \mathrm{min}]}\end{array}$} & \multirow{2}{*}{$\begin{array}{c}f \\
{[\mathrm{~mm} / \mathrm{rev}]}\end{array}$} & \multicolumn{3}{|c|}{ Measured primary $\gamma^{\prime}$} & \multicolumn{3}{|c|}{ Measured secondary $\gamma^{\prime}$} \\
\hline & & & $\begin{array}{c}\text { Mean } d_{1} \\
{[\mu \mathrm{m}]}\end{array}$ & $\begin{array}{l}S D d_{1} \\
{[\mu \mathrm{m}]}\end{array}$ & $\begin{array}{c}\text { Mean } \\
f_{1}\end{array}$ & $\begin{array}{c}\text { Mean } d_{2} \\
{[\mathrm{~nm}]}\end{array}$ & $\begin{array}{l}S D d_{1} \\
{[\mathrm{~nm}]}\end{array}$ & $\begin{array}{c}\text { Mean } \\
f_{2}\end{array}$ \\
\hline \multirow{2}{*}{$\mathrm{WC} / \mathrm{Co}, r_{\beta}=5 \mu \mathrm{m}$} & 12 & 0.05 & 0.83 & 0.24 & 0.114 & 135 & 45 & 0.28 \\
\hline & 24 & 0.05 & 0.94 & 0.25 & 0.106 & 163 & 45 & 0.28 \\
\hline \multirow{2}{*}{ TiAlN, $r_{\beta}=10 \mu \mathrm{m}$} & 12 & 0.05 & 0.88 & 0.26 & 0.145 & 154 & 48 & 0.24 \\
\hline & 24 & 0.05 & 0.73 & 0.22 & 0.060 & 167 & 49 & 0.27 \\
\hline \multirow{2}{*}{$\mathrm{WC} / \mathrm{Co}, r_{\beta}=10 \mu \mathrm{m}$} & 12 & 0.05 & 0.92 & 0.26 & 0.111 & 140 & 40 & 0.26 \\
\hline & 24 & 0.05 & 0.78 & 0.22 & 0.107 & 167 & 58 & 0.27 \\
\hline \multirow{2}{*}{$\mathrm{WC} / \mathrm{Co}, r_{\beta}=25 \mu \mathrm{m}$} & 12 & 0.05 & 0.97 & 0.27 & 0.092 & 141 & 39 & 0.28 \\
\hline & 24 & 0.05 & 0.81 & 0.22 & 0.065 & 150 & 45 & 0.30 \\
\hline
\end{tabular}

The effects of process parameters on grain sizes and volume fractions can be seen in Figures 18-19. Higher cutting speeds tend to yield smaller primary $\gamma^{\prime}$ precipitates $\left(d_{l}\right)$ but larger secondary $\gamma^{\prime}$ precipitates $\left(d_{2}\right)$ and increasing machining induced higher surface hardness alteration. Higher cutting speeds decrease the volume fraction of the primary $\gamma^{\prime}$ phase $\left(f_{I}\right)$, but increase the volume fraction of the secondary $\gamma^{\prime}$ phase $\left(f_{2}\right)$ also resulting in increased surface hardness (see Table 2). Uncoated WC/Co tools width edge radii of $r_{\beta}=5 \mu \mathrm{m}$ and $r_{\beta}=25 \mu \mathrm{m}$ yield larger primary $\gamma$ ' precipitates $\left(d_{l}\right)$, followed by the uncoated WC/Co tools with $r_{\beta}=10 \mu \mathrm{m}$ edge radius. Using TiAlN coated tool results in the smallest primary $\gamma^{\prime}$ grains and lower hardness alteration. An interesting observation is that these trends are reversed for the secondary $\gamma^{\prime}$ precipitate sizes where the TiAlN coated tool generates the largest secondary $\gamma^{\prime}$ grains. Moreover, TiAlN tool yields the lowest volume fraction of the secondary $\gamma^{\prime}$ phase whereas uncoated WC/Co tools with $r_{\beta}=10 \mu \mathrm{m}$ edge radius yield the lowest volume fraction of the primary $\gamma^{\prime}$ phase. 


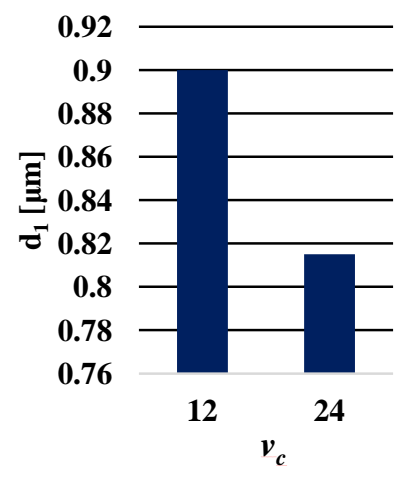

(a)

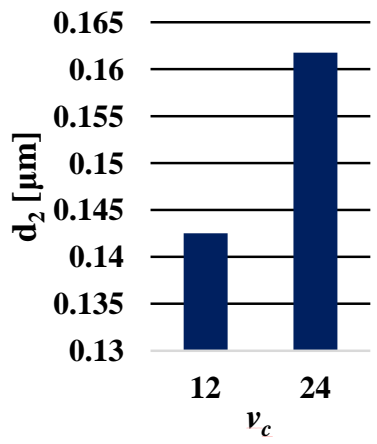

(c)

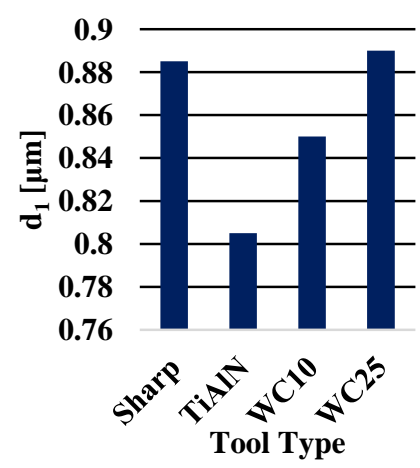

(b)

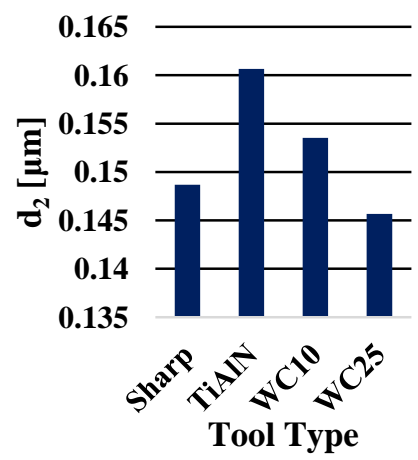

(d)

Fig. 18: Effects of cutting speed $v_{c}(\mathrm{a} \& \mathrm{c})$ and tool type and edge radius $(\mathrm{b} \& \mathrm{~d})$ on the primary $(\mathrm{a} \& \mathrm{~b})$ and secondary $(c \& d) \gamma^{\prime}$ grains.

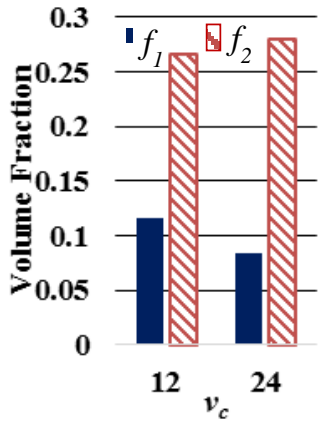

(a)

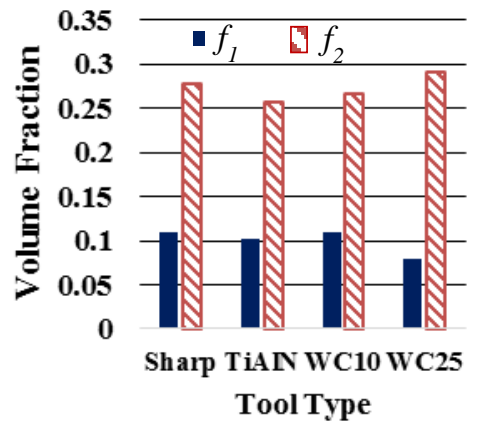

(b)

Fig. 19: Effects of cutting speed $v_{c}$ (left) and tool type (right) on the primary $\left(f_{1}\right)$ and secondary $\left(f_{2}\right) \gamma^{\prime}$ grain volume fractions. 
The effects of precipitate sizes and volume fractions on microhardness of machined surfaces are further analyzed in the predictive modeling section where a relationship between them and microhardness profiles are established through regression. Another important goal of this study is to obtain relevant microstructural information through computational modeling and simulations, which is achieved through finite element simulations and modeling in the next section.

\section{Finite Element Simulations and Microstructure Modeling}

3D FE simulations for face turning have been conducted for selected experimental conditions using DEFORM-3D software similar to the previous studies (Özel \& Ulutan 2012; Ulutan \& Özel 2013a; Arisoy \& Özel 2014). In the 3D FE simulations, the IN100 disk samples are represented by a segment using a curved workpiece geometry. The material was assumed to be viscoplastic, and elasticity was ignored. A higher mesh density was used in a $1 \mathrm{~mm}$-long section behind the chip to better resolve the temperature and strain fields that are necessary for the microstructure calculations on the machined surface as shown in Fig. 20.

In machining process simulations, friction at the tool-chip contact can be handled by using a hybrid model since normal stress can be high in sticking contact and low in sliding contact along the rake and flank faces. This hybrid model employs both the shear friction in the sticking contact region and Coulomb friction in the sliding region. The hybrid friction model uses normal contact stress as a reference to switch between shear and Coulomb friction models in DEFORM 3D software. The shear friction can be described as $m=\tau / k$ and Coulomb friction model is described as $\mu=\tau_{f} / \sigma_{n}$ where $\tau$ is material shear stress, $k$ is shear flow stress, $\tau_{f}$ is frictional stress and $\sigma_{n}$ is normal stress on the tool face. The shear friction $(0 \leq \mathrm{m} \leq 1)$ is used when $\sigma_{n}$ is high and Coulomb friction is used when $\sigma_{n}$ is low.

Therefore, the friction between the tool and the workpiece was described with this hybrid model including both shear friction and Coulomb friction along the rake and flank faces of the tool. Friction coefficients were determined by matching the experimental forces with 3D FE simulations under the perfect dry cutting conditions (Ulutan \& Özel 2013b). These friction coefficient ranges for dry cutting conditions $(0.5<\mu<0.8)$ are in the norm of the other literature as summarized in Arrazola et al. 2013. A shear friction factor of $m=0.9$ was used in all simulations. The values of shear friction and Coulomb friction are given in Table 4.

A very high heat transfer coefficient $\left(h=1.0 \times 10^{5} \mathrm{kWm}^{-2} \mathrm{~K}^{-1}\right)$ between tool and workpiece was used to allow temperature field to reach its steady-state in a short period of time. 


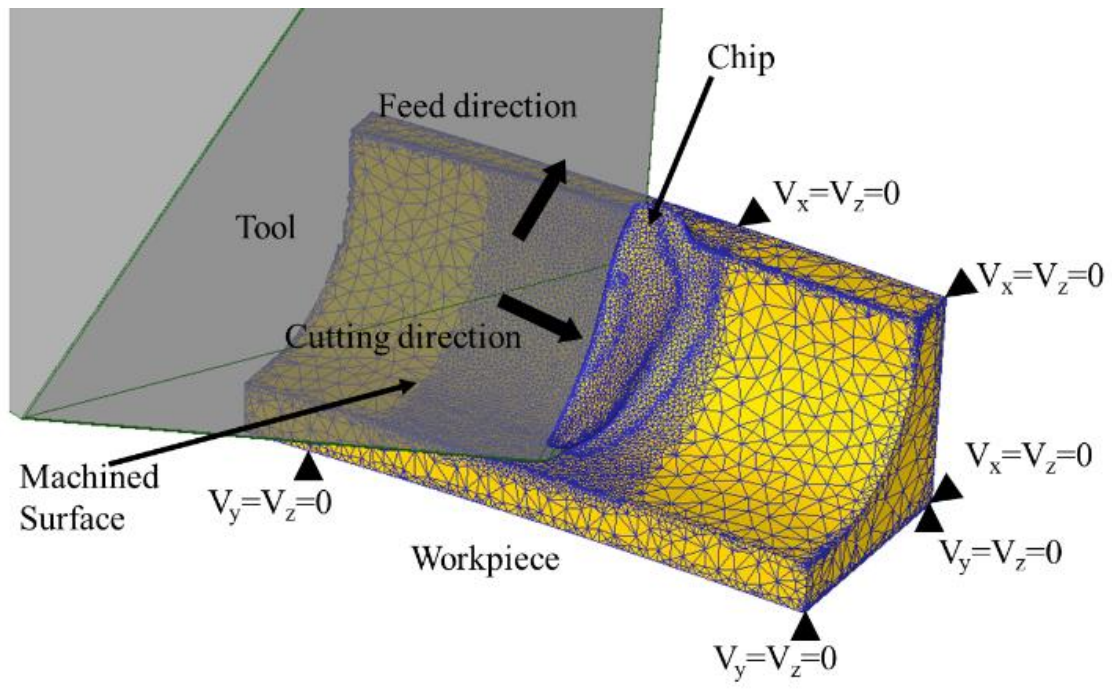

Fig. 20: 3D FE simulation model for turning IN100 alloy.

All 3D simulations were run until a fully grown chip formation occurred at a fixed cutting length at respective cutting speeds. Simulation results on predicted grain sizes were extracted from DEFORM-3D, and processed in MATLAB software over a selected volume (extending up to $3 \mathrm{~mm}$ behind the chip in the machined zone) for each simulation using normalized element volumes as weights to accurately represent the given volume.

Table 4: General parameters of the 3D machining Finite Element simulation (Ulutan \& Özel 2013b).

\begin{tabular}{|c|c|c|c|c|c|c|}
\hline \multicolumn{2}{|c|}{ Length [mm] } & \multicolumn{2}{c|}{ Number of elements } & Shear friction & \multicolumn{2}{c|}{ Coulomb friction coefficient } \\
\hline Workpiece & Cutting & Tool & Work & All surfaces & Rake surface & Flank surface \\
\hline 3.5 & 2.6 & 120,000 & 100,00 & $\mathrm{~m}=0.9$ & $\mu=0.8$ for WC/Co & $\mu=0.6$ for WC/Co \\
\cline { 6 - 7 } & & & & & $\mu=0.6$ for TiAlN & $\mu=0.5$ for TiAlN \\
\hline
\end{tabular}

A material constitutive model with modification to the Johnson-Cook (JC) model to represent temperaturedependent flow softening behavior of high temperature alloys has been used. The modified model is given with Eq. (3) where flow stress, $\sigma$, is being represented in terms of strain, $\varepsilon$, strain rate $\varepsilon^{*}$, and temperature and where $\varepsilon_{0}^{*}$ is the reference strain rate, $T_{0}$ is the ambient temperature, and $T_{m}$ is the melting point of the material. 


$$
\begin{gathered}
\sigma=\left[A+B \varepsilon^{n}\left(\frac{1}{\exp \left(\varepsilon^{a}\right)}\right)\right]\left[1+C \ln \frac{\dot{\varepsilon}}{\dot{\varepsilon}_{0}}\right]\left[1-\left(\frac{T-T_{r}}{T_{m}-T_{r}}\right)^{m}\right] \times\left[D+(1-D)\left[\tanh \left(\frac{1}{(\varepsilon+p)^{r}}\right)\right]^{s}\right] \\
\text { where } \quad D=1-\left(\frac{T}{T_{m}}\right)^{d} p=\left(\frac{T}{T_{m}}\right)^{b}
\end{gathered}
$$

This model includes the JC model parameters $(A, B, C, n, m)$ and modification parameters $(a, b, d, r, s)$ that are used to describe temperature-dependent flow softening. However, this modified Johnson-Cook material model does not present an explanation for the physical significance of all the parameters used such as D, b, d, p, r, and s. Rather, the model provides temperature-strain coupled flow softening mathematical model that follows temperature-dependent flow softening in flow stress. It should be noted that a stronger coupling between the grain sizes, the volume fraction of $\gamma$ matrix, primary/secondary $\gamma^{\prime}$ grains and the flow stress should have been achieved during the simulations. Currently, it is not possible to implement such a dynamic softening in DEFORM-3D since JMAK model for dynamic recrystallization is done as post-processing. Therefore, only the static softening phenomenon caused by the temperature term of modified Johnson-Cook constitutive equation is taken into account.

The modified JC model parameters have been determined for IN100 alloy by matching experimental and simulated forces through iterations in 3D FE simulations (Ulutan \& Özel 2013b) and are given in Table 5. Temperaturedependent physical, mechanical, and thermal properties of IN100 alloy along with tool material and coating used in FE simulations are given in Table 6.

Table 5: Material flow stress model parameters for IN100 alloy (Ulutan \& Özel 2013b).

\begin{tabular}{|c|c|c|c|c|c|c|c|c|c|}
\hline $\boldsymbol{A}$ & $\boldsymbol{B}$ & $\boldsymbol{n}$ & $\boldsymbol{C}$ & $\boldsymbol{m}$ & $\boldsymbol{A}$ & $\boldsymbol{b}$ & $\boldsymbol{d}$ & $\boldsymbol{r}$ & $\boldsymbol{s}$ \\
\hline 1350 & 1750 & 0.65 & 0.017 & 1.3 & 1.5 & 10 & 0.01 & 1.5 & -0.4 \\
\hline
\end{tabular}

Table 6: Temperature-dependent material properties (Özel \& Ulutan 2012).

\begin{tabular}{|c|c|c|c|}
\hline Property & WC $/ \mathbf{C o}$ & (Ti,Al)N & IN100 \\
\hline $\boldsymbol{E}[\mathbf{G P a}]$ & $5.6 \times 10^{5}$ & $6.0 \times 10^{5}$ & $72 \times T+217000$ \\
\hline $\boldsymbol{\alpha}\left[\mathbf{1} /{ }^{\circ} \mathbf{C}\right]$ & $4.7 \times 10^{-6}$ & $9.4 \times 10^{-6}$ & $1.1 \times 10^{-5}$ \\
\hline$\lambda\left[\mathbf{W} / \mathbf{m}^{\circ}{ }^{\circ} \mathbf{C}\right]$ & 55 & $0.0081 T+11.95$ & $10.3 \times \mathrm{e}^{0.008^{*} T}$ \\
\hline $\boldsymbol{c}_{\boldsymbol{p}}\left[\mathbf{N} / \mathbf{m m}^{2}{ }^{\circ} \mathbf{C}\right]$ & $5 \times 10^{-4} T+2.07$ & $0.0003 T+0.57$ & $3.62 \times \mathrm{e}^{0.0004^{*} T}$ \\
\hline
\end{tabular}


In 3D FE simulations, the Johnson-Mehl-Avrami-Kolmogorov (JMAK) model also known as Avrami model, which defines the transformation kinetics in a material, was used. The JMAK model calculates the recrystallized volume fraction inside the material as a function of temperature, strain, and strain rate, and then uses initial grain size information to model the microstructure evolution. In this model, a modified JMAK equation describes the volume fraction of the transformed material as a function of temperature and time. Arrhenius type equations can be used to describe model variables with respect to temperature, strain and strain rate obtained from the FE solution at a given step (Shen 2005). According to the JMAK model, dynamic recrystallization generally occurs when a critical strain $\varepsilon_{c}=a_{2}\left(\varepsilon_{p}\right)$ is reached, where the peak strain, $\varepsilon_{p}$, is defined as:

$$
\varepsilon_{p}=a_{1} d_{0}^{h_{1}} \dot{\varepsilon}^{m_{1}} \exp \left(Q_{a c t} m_{1} / R T\right)+c_{1}
$$

The dynamic recrystallization and subsequent fraction of dynamically recrystallized grains is defined with the Avrami equation as given with:

$$
X_{D R x}=1-\exp \left[-\beta_{d}\left(\frac{\varepsilon-a_{10} \varepsilon_{p}}{\varepsilon_{0.5}}\right)^{k_{d}}\right]
$$

where $\varepsilon$ is the strain, $\varepsilon_{p}$ is the peak strain, $X_{D R x}$ is the fraction of dynamically recrystallized material. The $\varepsilon_{0.5}$ symbolizes the strain value for $X_{D R x}=0.5$ and is given as:

$$
\varepsilon_{0.5}=a_{5} d_{0}^{h_{5}} \varepsilon^{n_{5}} \dot{\varepsilon}^{m_{5}} \exp \left(Q_{a c t} m_{5} / R T\right)+c_{5}
$$

where $R$ is the universal gas constant. The dynamically recrystallized grain size is then given with:

$$
d_{D R x}=a_{8} d_{0}^{h_{8}} \varepsilon^{n_{8}} \dot{\varepsilon}^{m_{8}} \exp \left(Q_{a c t} m_{8} / R T\right)+c_{8}
$$

The average grain size is calculated using the rule of mixtures:

$$
d_{\text {avg }}=d_{0}\left(1-X_{D R x}\right)+d_{D R x} X_{D R x}
$$

Note that Eqs. (4)-(8) are calculated at each time step for all elements during the simulation as a post processing operation.

Experimental microstructure results under hot deformation conditions are often used to determine the constants for recrystallized fraction and grain size (Shen et al. 1995; Shen 2005). In this study, the JMAK model parameters have been identified using Genetic Algorithm based optimization on the FE simulations to minimize the difference with predicted and measured average grain size for primary $\gamma^{\prime}$ grains under machining conditions. In simulations, an activation energy of $Q_{a c t}=348000 \mathrm{~J} / \mathrm{mol}$ (Kikuchi et al. 1990), and initial grain sizes of $d_{0}=3.5 \mu \mathrm{m}$ for $\gamma$ matrix grains and $d_{0}=1.28 \mu \mathrm{m}$ for primary $\gamma^{\prime}$ grains (Milligan et al. 2014) were used. The final set of JMAK model parameters for IN100 alloy has been identified after running parameter optimization simulations by initially basing off the JMAK parameters for Waspoloy (Shen 2005) as shown in Table 7. 
Table 7: The JMAK model parameters for IN100 alloy.

\begin{tabular}{|c|c|c|c|c|c|}
\hline $\boldsymbol{a}_{\mathbf{1}}$ & $\boldsymbol{h}_{\mathbf{1}}$ & $\boldsymbol{m}_{1}$ & $\boldsymbol{c}_{\boldsymbol{1}}$ & $\boldsymbol{a}_{2}$ & $\boldsymbol{\beta}_{\boldsymbol{d}}$ \\
\hline 0.293 & 0.34 & 0.039 & 0 & 0.38 & 0.693 \\
\hline $\boldsymbol{a}_{5}$ & $\boldsymbol{h}_{5}$ & $\boldsymbol{m}_{5}$ & $\boldsymbol{n}_{5}$ & $\boldsymbol{c}_{5}$ & $\boldsymbol{k}_{\boldsymbol{d}}$ \\
\hline 0.145 & 0.48 & 0.03 & 0 & 0 & 3 \\
\hline $\boldsymbol{a}_{\boldsymbol{8}}$ & $\boldsymbol{h}_{\boldsymbol{8}}$ & $\boldsymbol{m}_{\boldsymbol{8}}$ & $\boldsymbol{n}_{\boldsymbol{8}}$ & $\boldsymbol{c}_{\boldsymbol{8}}$ & $\boldsymbol{a}_{10}$ \\
\hline 8103 & 0 & -0.16 & 0.43 & 0 & 0 \\
\hline
\end{tabular}

\section{Microstructure Predictions}

In this section, we explore the relationships between process conditions and the experimental microhardness and microstructure data, along with 3D FE simulations for the IN100 alloy, and develop predictive models for these.

\subsection{Finite Element simulation results for microstructure}

3D Finite Element machining simulations have been utilized to evaluate dynamic recrystallization for both $\gamma$-matrix grains and primary $\gamma^{\prime}$ grains. By using the JMAK model described in Eq. (4-8) and Avrami mixture of original grains $\left(d_{0}\right)$, recrystallized grains $\left(d_{D R x}\right)$ and the volume fraction of the dynamic recrystallization $\left(X_{D R x}\right)$, predicted average grain sizes for $\gamma$ matrix grains as $d_{\text {avg }}$ and for $\gamma^{\prime}$ grains as $d_{l}$ have been computed as post-processing of temperature, strain, and strain -rate fields in 3D FE simulation. Therefore no predictions for secondary and tertiary $\gamma^{\prime}$ grains are presented here.

Using the 3D Finite Element simulations described in the previous section, temperature, dynamic recrystallized volume fractions $\left(X_{D R x}\right)$, dynamic recrystallized grain sizes $\left(d_{D R x}\right)$, and average grain sizes including the recrystallized grains for both $\gamma$-matrix grains and primary $\gamma^{\prime}$ grains have been extracted using MATLAB, and histograms together with mean and standard deviations have been obtained. These predicted field variables and measured average grain sizes are given in Table 8. It should be noted that there is no measurement reported on $\gamma$ matrix grains and tertiary $\gamma^{\prime}$ grains due to the explained difficulties. 
Table 8: Predicted microstructure variables and measured primary $\gamma^{\prime}$ grain sizes obtained from a face turning 3D finite element simulation.

\begin{tabular}{|c|c|c|c|c|c|c|c|c|c|c|}
\hline \multirow{3}{*}{ Tool } & \multirow{3}{*}{$\begin{array}{c}v_{c} \\
{[\mathrm{~m} / \mathrm{min}]}\end{array}$} & \multirow{3}{*}{$\begin{array}{c}f \\
{[\mathrm{~mm} / \mathrm{rev}]}\end{array}$} & \multicolumn{7}{|c|}{ Predicted field variables } & \multirow{3}{*}{$\begin{array}{c}\text { Measured } \\
\text { primary } \gamma^{\prime} \\
\text { grain size } \\
d_{1} \\
{[\mu \mathrm{m}]}\end{array}$} \\
\hline & & & \multirow{2}{*}{$T\left[{ }^{\circ} \mathrm{C}\right]$} & \multicolumn{3}{|c|}{$\begin{array}{c}\gamma \text { matrix grains } \\
\left(d_{0}=3 \mu \mathrm{m}\right)\end{array}$} & \multicolumn{3}{|c|}{$\begin{array}{c}\text { primary } \gamma^{\prime} \text { grains } \\
\left(d_{0}=1.28 \mu \mathrm{m}\right)\end{array}$} & \\
\hline & & & & $X_{D R x}$ & $\begin{array}{c}d D R x \\
{[\mu \mathrm{m}]}\end{array}$ & $\begin{array}{c}d_{a v g} \\
{[\mu \mathrm{m}]}\end{array}$ & $X_{D R x}$ & $\begin{array}{c}d_{D R x} \\
{[\mu \mathrm{m}]}\end{array}$ & $\begin{array}{c}d_{1} \\
{[\mu \mathrm{m}]}\end{array}$ & \\
\hline \multirow{2}{*}{$\begin{array}{l}\text { WC/Co } \\
r_{\beta}=5 \mu \mathrm{m}\end{array}$} & 12 & 0.05 & 383 & 0.35 & 0.21 & 2.01 & 0.35 & 0.14 & 0.78 & 0.83 \\
\hline & 24 & 0.05 & 552 & 0.30 & 0.27 & 2.33 & 0.30 & 0.16 & 0.89 & 0.94 \\
\hline \multirow{2}{*}{$\begin{array}{c}\text { TiAlN } \\
r_{\beta}=10 \mu \mathrm{m}\end{array}$} & 12 & 0.05 & 359 & 0.36 & 0.22 & 1.99 & 0.36 & 0.15 & 0.79 & 0.88 \\
\hline & 24 & 0.05 & 524 & 0.31 & 0.26 & 2.28 & 0.32 & 0.16 & 0.88 & 0.73 \\
\hline
\end{tabular}

Dynamic recrystallized volume fraction is found about 30-35\% for both $\gamma$ matrix and primary $\gamma^{\prime}$ grains in IN100 alloy. Both $\gamma$ matrix and primary $\gamma^{\prime}$ grain sizes become smaller $(<2.0 \mu \mathrm{m}$ and $<0.9 \mu \mathrm{m}$ respectively) in all machining conditions indicating that the recrystallized grains contribute to resultant smaller average grain size hence machining affected microstructure caused by severe plastic deformation and excessive thermal loading (M'Saoubi et al. 2014). It should be noted that grain growth is not being considered due to rapid cooling rates of the machined surfaces. The ranges of measured grain sizes are in the ranges of predictions made with FE simulations. A comparison plot for predicted and measured average grain size for primary gamma prime $\left(\gamma^{\prime}\right)$ grains is given in Fig. 21 indicating mostly reasonable agreements. In addition, 3D FE simulation outputs of average grain sizes of both $\gamma$ matrix and primary $\gamma^{\prime}$ grains for machined surfaces using uncoated WC/Co and TiAlN coated tools are shown in Fig. 22.

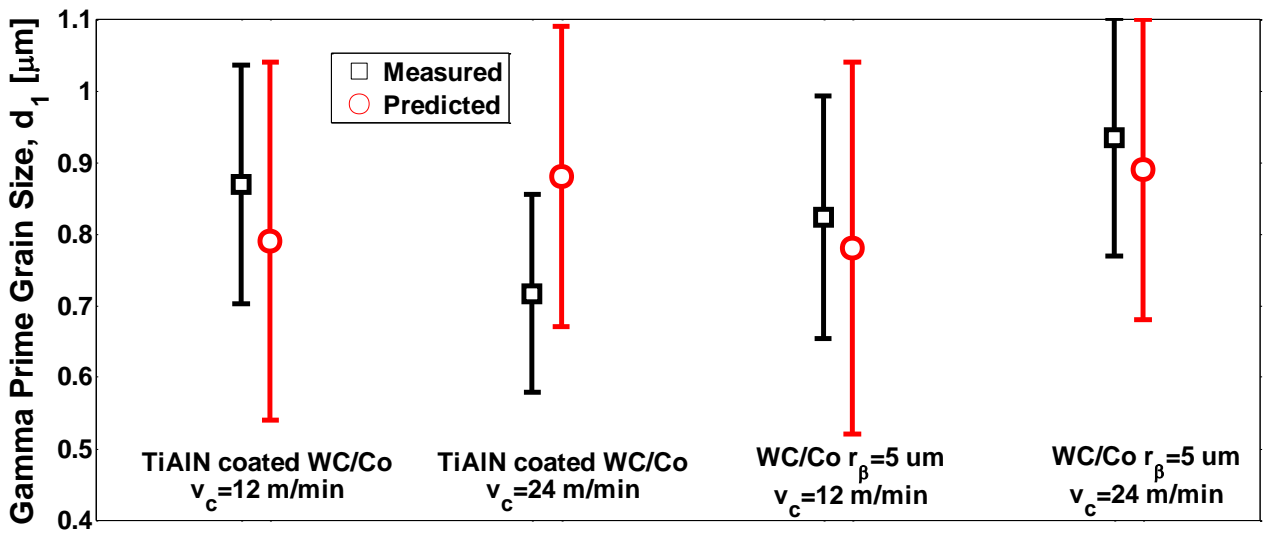

Fig. 21: Comparison of predicted and measured (primary $\gamma^{\prime}$ ) average grain size (mean and standard deviation) on IN100 alloy subsurface. 


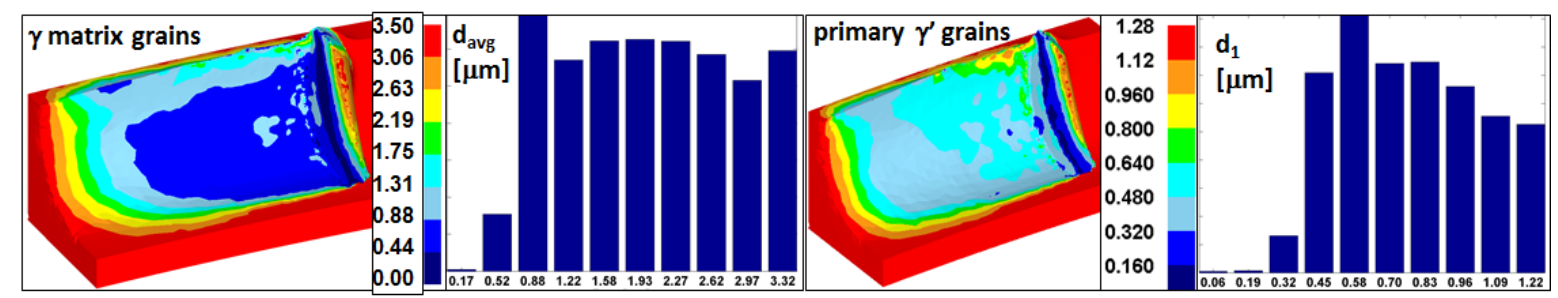

(a)

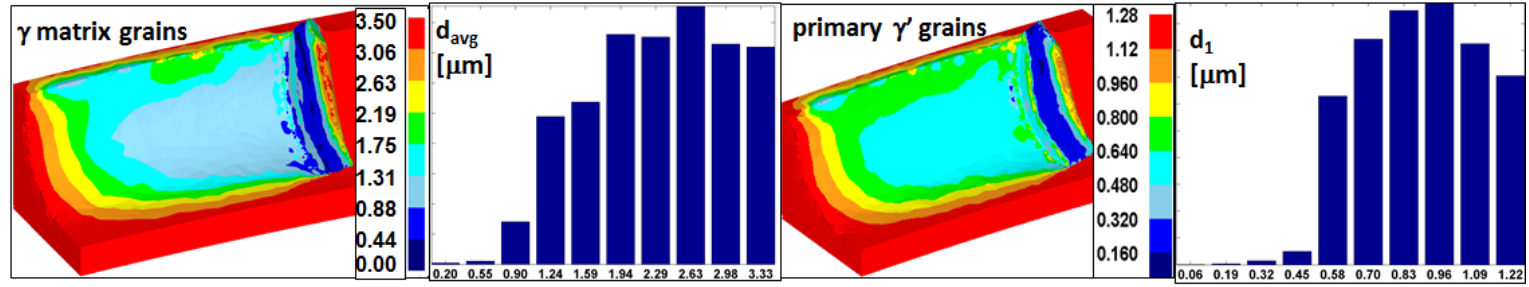

(b)

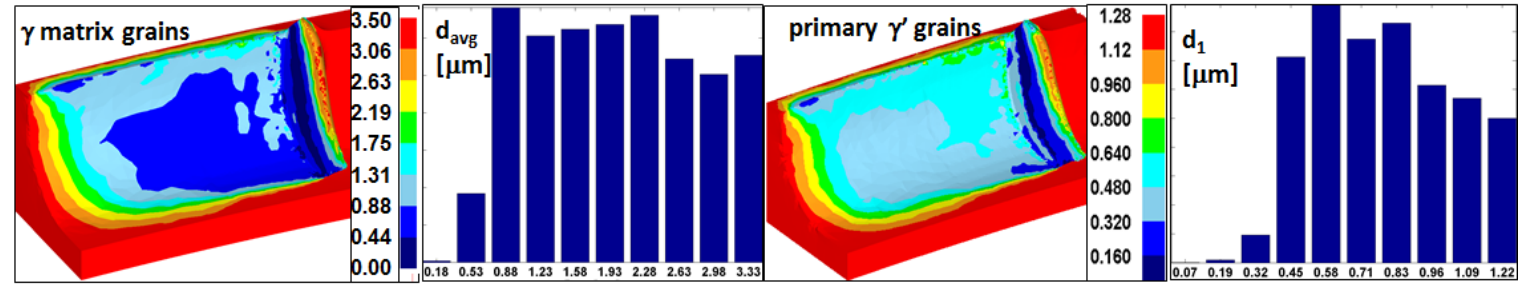

(c)

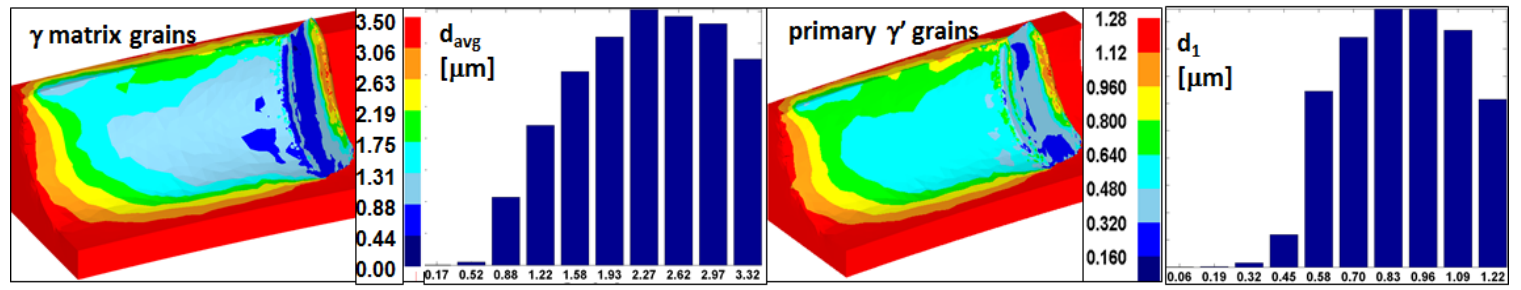

(d)

Fig. 22: Predicted grain size fields: (a) TiAlN coated tool $v_{c}=12 \mathrm{~m} / \mathrm{min}$, (b) $v_{c}=24 \mathrm{~m} / \mathrm{min}$, (c) WC/Co tool $r_{\beta}=5 \mu \mathrm{m}, v_{c}=12 \mathrm{~m} / \mathrm{min},(\mathrm{d}) v_{c}=24 \mathrm{~m} / \mathrm{min}$. 


\subsection{Microstructure based hardness predictions}

An important aspect of understanding machining induced hardness as function of microstructural alterations is to establish relationships between resultant subsurface microhardness and grain sizes with phase fractions. Using the grain sizes and distributions obtained via SEM and FEM analysis, an expression is constructed for predictive modeling of hardness on the machined subsurface (at about $25 \mu \mathrm{m}$ into the depth) as suggested in Milligan et al. (2004). Following this Hall-Petch type approach, a generalized model of the following form is proposed:

$$
H V=c_{0}+c_{1}\left[d_{1}^{m_{1}} f_{1}^{n_{1}}\right]+c_{2}\left[d_{2}^{m_{2}} f_{2}^{n_{2}}\right]+c_{3}\left[d_{3}^{m_{3}} f_{3}^{n_{3}}\right]+c_{4}\left[d_{\text {avg }}^{m_{4}}\right]
$$

where $\mathrm{HV}$ is microhardness, $d_{\text {avg }}, d_{1}, d_{2}, d_{3}$ are the $\gamma$-matrix, primary, secondary and tertiary $\gamma^{\prime}$ grain sizes and $f_{1}, f_{2}$, $f_{3}$ are related volume fractions, respectively. The $c_{0}, c_{1}, c_{2}, c_{3}, c_{4}$ are model constants and $m_{1}, n_{1}, m_{2}, n_{2}, m_{3}, n_{3}, m_{4}$ are model exponents. Model parameters are obtained via nonlinear optimization using genetic algorithm from SEM measurements for gamma prime grain sizes and volume fractions, $\gamma$ matrix grain sizes calculated from 3D FE simulations along with the microhardness measurements (see Table 9).

Table 9: Summary of grain sizes and volume fractions utilized in the model.

\begin{tabular}{|c|c|c|c|c|c|c|c|c|c|}
\hline \multirow{2}{*}{ Tool } & \multirow{2}{*}{$\begin{array}{c}v_{c} \\
{[\mathrm{~m} / \mathrm{min}]}\end{array}$} & \multirow{2}{*}{$\begin{array}{c}f \\
{[\mathrm{~mm} / \mathrm{rev}]}\end{array}$} & \multirow{2}{*}{$\begin{array}{l}\text { Predicted } \\
d_{\text {avg }}[\mu \mathrm{m}]\end{array}$} & \multicolumn{2}{|c|}{ Measured } & \multirow{2}{*}{\begin{tabular}{|l} 
Literature \\
$d_{3}[\mathrm{~nm}]$
\end{tabular}} & \multicolumn{2}{|c|}{ Measured } & \multirow{2}{*}{\begin{tabular}{|c} 
Literature \\
$f_{3}$
\end{tabular}} \\
\hline & & & & $d_{1}[\mu \mathrm{m}]$ & $d_{2}[\mathrm{~nm}]$ & & $f_{1}$ & $f_{2}$ & \\
\hline WC/Co & 12 & 0.05 & 2.01 & 0.83 & 135 & 10 & 0.114 & 0.28 & 0.042 \\
\hline$r_{\beta}=5 \mu \mathrm{m}$ & 24 & 0.05 & 2.33 & 0.94 & 163 & 10 & 0.106 & 0.28 & 0.042 \\
\hline TiAlN & 12 & 0.05 & 1.99 & 0.88 & 154 & 10 & 0.145 & 0.24 & 0.042 \\
\hline$r_{\beta}=10 \mu \mathrm{m}$ & 24 & 0.05 & 2.28 & 0.73 & 167 & 10 & 0.060 & 0.27 & 0.042 \\
\hline
\end{tabular}

The resultant microhardness model for IN100 which can be used for hardness predictions is given as:

$$
H V=110.36+168.75\left[d_{1}^{0.38} f_{1}^{0.007}\right]+2858.91\left[d_{2}^{-0.74} f_{2}^{0.35}\right]+60.97\left[d_{3}^{-0.33} f_{3}^{0.41}\right]+97.43\left[d_{\text {avg }}^{0.25}\right]
$$

The model has $\mathrm{R}^{2}=0.8$, indicating that there are other factors that contribute to the hardness. The model is compared to experimental data on microhardness profile measurements in Fig. 5 as shown in Fig. 23. It provides a fine match and could be used to estimate the hardness of "white layer formation" from measured or predicted grains sizes and phase fractions.

It should be noted that this proposed relationships of the estimated hardness is only empiric but it can also be used to fit observed experimental data. 


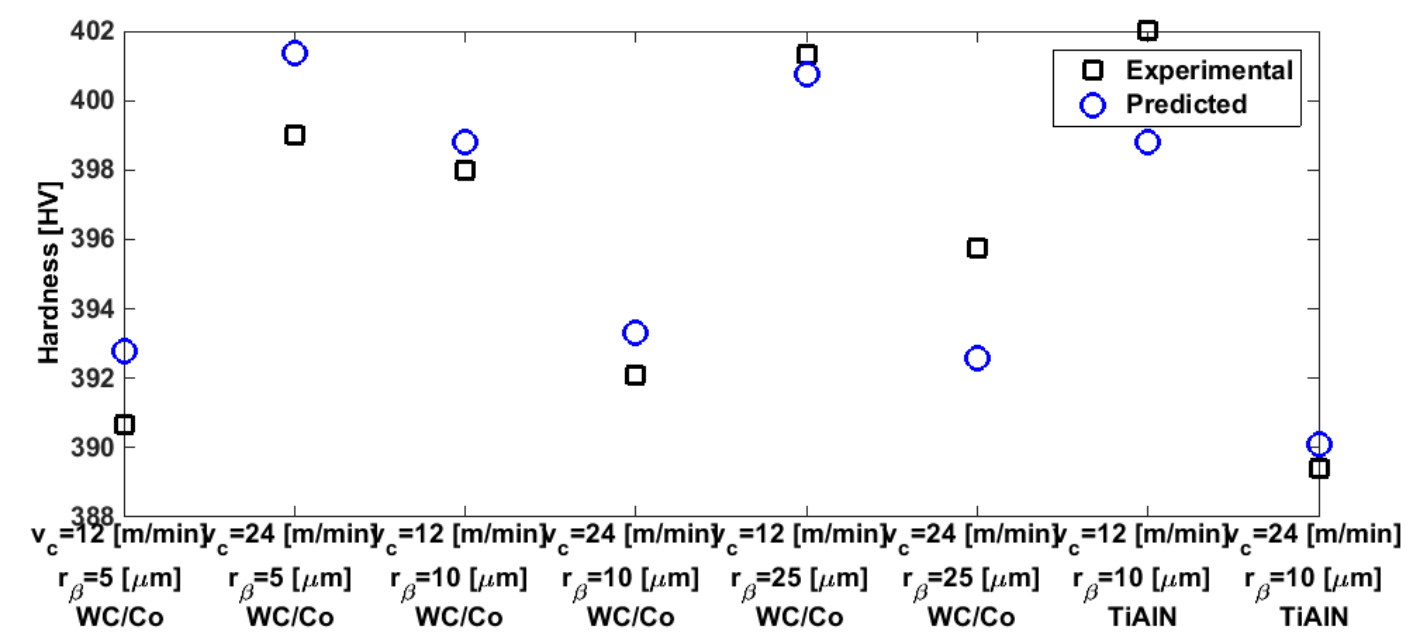

Fig. 23: Comparison of experimental microhardness measurements and grain-size based microhardness predictions.

\section{Conclusions}

In this study, machining induced surface integrity and microstructure in IN100 nickel-base alloy has been investigated. Machining experiments have been conducted with varying cutting speeds, tool edge radii and coating, and SEM images have been taken at the machined surfaces after preparation. Microhardness measurements have been taken at various depths below the machined surface. Higher microhardness levels have been observed at the machined surfaces and the hardness profile decades into the depth of the material. These measurements indicate that the high hardness layer is about $25 \mu \mathrm{m}$ thick below the surface. The uncoated $\mathrm{WC} / \mathrm{Co}$ tool with largest edge radius resulted in high microhardness levels where the TiAlN coated WC/Co tool resulted in lowest hardness levels at the higher cutting speed of $24 \mathrm{~m} / \mathrm{min}$. At the lower cutting speed the uncoated WC/Co tool with sharp edge provided the lower overall hardness levels on the machined surfaces but slightly higher than TiAlN coated tool at the hardened layer which is about $25 \mu \mathrm{m}$ depth into the surface.

Microstructure investigations have been conducted in order to quantify the grain size and volume fraction of primary and secondary gamma prime $\left(\gamma^{\prime}\right)$ grains. The measurements performed on precipitate sizes and volume fractions, as well as the microhardness depth profiles presented in this study provide an insight for effects of process parameters on the surface integrity in machining of IN100 alloy.

Furthermore, 3D FE simulations are conducted for microstructure modeling based on a modified Johnson-MehlAvrami-Kolmogorov (JMAK) model, and dynamic recrystallization (volume fraction and DRx grain size) and resultant average grain sizes of gamma $(\gamma)$ and gamma prime $\left(\gamma^{\prime}\right)$ phases have been calculated on machined surfaces. Substantial recrystallization with dynamic recrystallized volume fraction of 30-35\% has been predicted and resultant average grain sizes $(<0.9 \mu \mathrm{m})$ have been compared with measured grain sizes indicating reasonable agreements. A Hall-Petch type equation is utilized to predict hardness at $120 \mu \mathrm{m}$ depth from primary and secondary $\gamma^{\prime}$ grains. Predictive models have been created using regression that relates hardness to cutting conditions. Developed models 
suggest that in machining of IN100, the primary $\gamma^{\prime}$ precipitate size $\left(d_{1}\right)$ causes an increase in the hardness of the surface, whereas larger $f_{1}, d_{2}$ and $f_{2}$ cause softening.

\section{Acknowledgements}

The financial support by United States National Science Foundation through grant CMMI-1130780 and work material and properties provided by United Technologies Research Center, Connecticut, USA, and microhardness measurement and analysis collaboration with ATILIM University Metal Forming Center of Excellence, Ankara, Turkey has been gratefully acknowledged. 


\section{References}

Arisoy, Y.M., Özel, T. (2014) Prediction of Machining Induced Grain Size with FE-Based Simulations of Ti-6Al4V and IN-100 Alloys using the Johnson-Mehl-Avrami-Kolmogorov Model. Proceedings of the 42nd North American Manufacturing Research Conference, June 9-13, 2014, Detroit, Michigan, USA.

Arısoy, Y.M., Özel, T. (2015) Investigations on Machining Induced Microstructural Changes on Inconel 100, Proceedings of 2015 ASME International Conference on Manufacturing Science and Engineering, Paper No. MSEC2015-9318, June 8-12, 2015, Charlotte, North Carolina, USA.

Arrazola, P.J., Özel, T., Umbrello, D.,Davies, M., Jawahir, I.S. (2013) Recent advances in modelling of metal machining processes. CIRP Annals-Manufacturing Technology 62(2): 695-718.

Arunachalam, R.M., Mannan, M.A., Spowage, A.C. (2004) Surface integrity when machining age hardened Inconel 718 with coated carbide cutting tools, International Journal of Machine Tools and Manufacture 44(14): 1481-1491.

Aspinwall, D.K., Dewes, R.C., Ng, E.-G., Sage, C., Soo, S.L. (2007) The influence of cutter orientation and workpiece angle on machinability when high-speed milling Inconel 718 under finishing conditions, International Journal of Machine Tools and Manufacture 47(12-13): 1839-1846.

Axinte, D.A., Andrews, P., Li, W., Gindy, G., Withers, P.J., Childs, T.H.C. (2006) Turning of advanced Ni based alloys obtained via powder metallurgy route, CIRP Annals-Manufacturing Technology 55(1):117-120.

Ezugwu, E.O., Wang, Z.M., Machado, A.R. (1999) The Machinability of Nickel-based Alloys: A Review. Journal of Materials Processing Technology 86:1-16.

Jawahir, I.S., Brinksmeier, E., M'Saoubi, R., Aspinwall, D.K., Outeiro, J.C.,Meyer, D., Umbrello, D., Jayal, A.D. (2011) Surface integrity in material removal processes: Recent advances. CIRP Annals-Manufacturing Technology 60: 603-626.

Kikuchi, S., Ando, S., Futami, S., Kitamura, T., Koiwa, M. (1990) Superplastic deformation and microstructure evolution in PM IN-100 superalloy. Journal of Material Science 25: 4712-4716.

M'Saoubi, R., Axinte, D., Herbert, C., Hardy, M., Salmon, P. (2014) Surface integrity of nickel-based alloys subjected to severe plastic deformation by abusive drilling CIRP Annals - Manufacturing Technology 63: 61-64.

Milligan, W.W., Orth, E.L., Schirra, J.J., Savage, M.F. (2004) Effects of microstructure on the high temperature constitutive behavior of IN100, Superalloys TMS (The Minerals, Metals \& Materials Society): 331-339.

Özel, T., Ulutan, D., (2012) Prediction of machining induced residual stresses in turning of titanium and nickel based alloys with experiments and finite element simulations. CIRP Annals-Manufacturing Technology 61: 547550. 
Özel, T., Arisoy, Y.M. (2014) Experimental and Numerical Investigations on Machining Induced Surface Integrity in Inconel-100 Nickel-Base Alloy. Procedia CIRP, 13: 302-307, Proceedings of 2nd CIRP Conference on Surface Integrity (CSI), May 28-30, 2014, Nottingham, U.K.

Özel, T., Ulutan, D. (2012) Prediction of machining induced residual stresses in turning of titanium and nickel based alloys with experiments and finite element simulations. CIRP Annals-Manufacturing Technology 61: 547-550.

Pawade, R.S., Joshi, S.S., Brahmankar, P.K. (2008) Effect of Machining Parameters and Cutting Edge Geometry on Surface Integrity of High-Speed Turned Inconel 718. International Journal of Machine Tools and Manufacture 48: $15-28$.

Ranganath, S., Guo C., Hegde P. (2009) A finite element modeling approach to predicting white layer formation in nickel superalloys, CIRP Annals - Manufacturing Technology 58(1): 77:80.

Shen, G., Semiatin, S.L., Svihpuri, R. (1995) Modeling Microstructural Development during the Forging of Waspaloy. Metall Mater Trans A, 26(7):1795-1803.

Shen, G. (2005) Microstructure modeling in superalloy forging in cold and hot forging Fundamentals and Applications. Editors Altan T., Ngaile G., Shen G., ASM International, 247-245.

Snenoy, M, Tjiptowidjojo, Y., McDowell, D. (2008) Microstructure-sensitive modeling of polycrystalline IN 100. International Journal of Plasticity, 24(10): 1694-1730.

Ulutan, D., Özel, T. (2011) Machining induced surface integrity in titanium and nickel alloys: a review. International Journal of Machine Tools Manufacture 51: 250-280.

Ulutan, D., Özel, T. (2013a) Multi-objective optimization of experimental and simulated residual stresses in turning of nickel-alloy IN100. Materials and Manufacturing Processes 28(7): 835-841.

Ulutan, D., Özel, T. (2013b) Determination of constitutive material model parameters in FE-based machining simulations of Ti-6Al-4V and IN-100 alloys: an inverse methodology, Proc 41st NAMRC, June 10-14, 2013, Wisconsin, USA.

Ulutan, D., Arisoy, Y.M., Özel, T., Mears, L. (2014) Empirical modeling of residual stress profile in machining nickel-based superalloys using the sinusoidal decay function, Procedia CIRP, Vol.13, 2014, pp. 365-370, Proceedings of 2nd CIRP Conference on Surface Integrity (CSI), May 28-30, 2014, Nottingham, U.K.

Wusatowska-Sarnek, A.M., Blackburn, M.J., Aindow, M. (2003a) Techniques for microstructural characterization of powder-processed nickel-based superalloys. Material Science Engineering A360: 390-395.

Wusatowska-Sarnek, A.M., Ghosh, G., Olson, G.B., Blackburn, M.J., Aindow, M. (2003b) Characterization of the microstructure and phase equilibria calculations for the powder metallurgy superalloy IN100. Journal of Materials Research 18(11): 2653-2663. 
Yuan, H., Liu, W.C. (2005) Effect of the $\delta$ phase on the hot deformation behavior of Inconel 718. Materials Science and Engineering A 408: 281-289.

Zhang, B., Mynors, D.J., Mugarra, A., Ostolaza, K. (2004) Representing the superplasticity of Inconel 718. Journal of Materials Processing Technology 153-154: 694-698. 